\title{
CONTEXTO DE LA POLÍTICA TARIFARIA RESIDENCIAL DEL SECTOR ELÉCTRICO Y ESTIMACIÓN DE LA FUNCIÓN CONSUMO ELÉCTRICO RESIDENCIAL: EL CASO DE MEXICALI, BAJA CALIFORNIA (1990-1992)*
}

\author{
Por \\ Agustún Sández Pérez** \\ RESUMEN
}

\begin{abstract}
En este artículo se plantean diversos aspectos de la problemática del consumo eléctrico en el noroeste del país, y particularmente en Mexicali, Baja California. Se resalta la especificidad de la demanda en la región, donde se requiere de un replanteamiento de su estilo de desarrollo orientado hacia un uso racional de la energía eléctrica. Asimismo, se subraya la necesidad de revisar mecanismos que permitan financiar el crecimiento del sector eléctrico. Basado en diversas fuentes y en los resultados de la Encuesta sobre el grado de adecuación ambiental de la vivienda y consumo eléctrico en Mexicali, se estudian las características del consumo eléctrico residencial y su relación con el nivel socioeconómico de los usuarios. Se expone también el contex to de las políticas en dicho sector y la problemática en la determinación de tarifas eléctricas. Finalmente, se analiza el modelo de la función consumo eléctrico residencial, que para el caso de estudio, presenta un importante contenido estacional.
\end{abstract}

\begin{abstract}
This article sets up several aspects about the problem of the electricity in take in the northwest of the country, particularly in Mexicali, Baja Califormia. The specificity of the demand in the region is relieved, where it's required a retracing of their development style oriented to a rational use of electricity. Also it is emphasized the necessity of checking the mechanisms that allow to finance the growth of the electricity sector. Based on several sources and the results of the survey about the environmental suitability degree of the tenement and electricity consume in Mexicali, the characteristics of housing electricity in take and their relation to the socioeconomic level of the users are studied. It's also exposed the context of the policies in such sector, and the problem about the electricity rates. Finally, the model of the function of the housing electricity in take is analyzed, which presents an important seasonal content.
\end{abstract}

- Este proyecto fue apoyado por un convenio con el H. XIII Ayuntamiento de Mexicali en su etapa inicial, y posteriormente por el Consejo Nacional de Ciencia y Tecnología (Conacyt). ** Director del Instítuto de Investigaciones Sociales de la Universidad Autónoma de Baja Califomia. E-mail: asandez@faro.ens.uabc.mx

N. del E. Este artículo se aprobó en junio de 1997 para su publicación en Estudios Fronterizos. 


\section{INTRODUCCIÓN}

En el transcurso de la presente investigacion pudieron puntualizarse varios aspectos sustanciales en el análisis de la problemática del sector eléctrico. En este sentido se ha identificado la necesidad para este sector de revisar mecanismos que permitan financiar su crecimiento. El noroeste de México y muy particularmente Baja California, requieren un replanteamiento sustantivo de su estilo de desarrollo orientado hacia un uso racional de la energía eléctrica.

Las características del consumo eléctrico en el noroeste del país lo convierten en un aspecto relevante en la planeación de su desarrollo. La particularidad de la demanda de energía eléctrica de los habitantes del valle de Mexicali resulta por demás específica.

La relación entre ahorro de energía y gestión ambiental resulta altamente interactiva. La literatura y evidencia empírica disponible en el estudio de caso permiten documentar una inelasticidad de la demanda de energía, aunque igualmente se señala la posibilidad de obtener mayores valores después de cierto umbral de ingreso.

La regulación de empresas de servicio público ha sido objeto de intensa crítica a partir de mediados de los ochenta. Se ha argumentado en favor de comisiones reguladoras cuya integración surja de una base participativa.

En materia de tarifas por servicio eléctrico tendrá que considerarse con mayor seriedad la distancia política y geográfica entre los diseñadores de política y las áreas afectadas, pues surge la posibilidad de que algunas regiones resulten más vulnerables que otras a modificaciones tarifarias.

La racionalidad de una estructura tarifaria básica implica el propósito de proveer de montos básicos de electricidad a bajo precio a la vez que se promueve el ahorro de energía. Los hogares de bajos ingresos requieren ser asistidos aunque la forma de hacerlo no sea fácil.

La función consumo eléctrico residencial presenta en el caso de estudio un considerable contenido estacional. Resultados estadísticos de algunas investigaciones realizadas han permitido situar con precisión que la demanda eléctrica se asocia positivamente con el nivel socioeconómico del hogar durante los meses de verano.

En el modelo, la proporción explicada de la varianza del consumo es aún insuficiente. Con esto se indica que su grado de ajuste sugiere la inclusión de factores adicionales en la explicación del fenómeno. En particular, se hace necesaria la incorporación de un conjunto amplio que identifique el tipo de actividad familiar (patrones de utilización y estilos de vida). 


\section{ANTECEDENTES}

\section{Desarrollo y consumo eléctrico en México}

Hacia fines de los ochenta el desempeño de la actividad de importantes sectores económicos en México entra en un franco periodo de transición. Nuevos esquemas organizacionales y de financiamiento para las empresas del sector público, conducen a una revisión de los procesos de determinación de precios y tarifas, a la vez que llevan a replantear sus formas de crecimiento.

En materia energética, el país ha dependido en alta proporción de energía primaria convencional proveniente de los hidrocarburos. Por ello, su uso racional y el desarrollo de capacidad tecnológica resultan imprescindibles.

Se han señalado como serias dificultades para la política energética mexicana, primero, su elevada dependencia de una sóla fuente no renovable; segundo, no lograr satisfacer los requerimientos de toda la población; tercero, persistente desperdicio e ineficiencia en el uso de los recursos.

En términos de generación eléctrica, de la capacidad total instalada en el sistema nacional, se estima que cerca de un $60 \%$ corresponde a centrales que operan quemando hidrocarburos y $40 \%$, se produce por hidroeléctricas, carboeléctricas y geotérmicas (CFE, 1991).

Las políticas del sector eléctrico nacional, durante mucho tiempo, se han regido por criterios sustentados en un notable aunque poco selectivo estímulo al desarrollo de la actividad productiva. El agotamiento del modelo de desarrollo industrial sustitutivo y el replanteamiento de la relación entre Estado y sector privado, obligan a reconsiderar los mecanismos de financiamiento para la operación y expansión de las empresas del sector público. Tal condición promueve ahora ajustes a los esquemas de recuperación, especialmente en sectores que ejercen significativa presión sobre la disponibilidad de recursos públicos.

Cabe señalar que el enfoque sectorial empleado en la fundamentacion y diseño de políticas - sin tratarse de una situación exclusiva del sector eléctrico-, requiere la incorporación de criterios óptimos de regionalización y de mayor definición en sus objetivos sociales, en vista de impulsar con eficacia mayor equidad regional y social.

La determinación de tarifas en servicios provistos por el sector público, como sería el caso de la electricidad, por mucho tiempo se ha orientado con criterios que significan una ventaja considerable para sectores de demanda que hacen consumos intensivos en actividades productivas. Por 
su parte, en el componente social del consumo, se desfavorece gradual e implícitamente a sectores de menores ingresos.

En el contexto del proceso anterior y frente a un conjunto especifico de condiciones regionales, este estudio ilustra la relevancia de criterios complementarios al diseño y aplicación de programas orientados al impulso del uso racional de la energía eléctrica.

\section{Consumo eléctrico en el noroeste de México}

Un breve examen de la dinámica reciente de crecimiento en la capacidad de generación eléctrica instalada, en especial, de una etapa en que su financiamiento registra importantes cambios, permite identificar cambios sustanciales en su contenido regional.

Es así que, a partir de la segunda mitad de los setenta, destaca el ritmo de expansión de los sistemas interconectados en la región noroeste - sin incluir a Baja California-, y de la región noreste. El primero mantuvo permanentemente su dinamismo muy por arriba de la media nacional durante una década, mientras el segundo rebasa este nivel a partir de 1981.

En situación opuesta, sistemas interconectados sur, norte y el correspondiente a Baja California, se mantienen sistemáticamente por debajo del ritmo promedio nacional. No resulta diff́cil identificar esta expansión con requerimientos asociados al crecimiento industrial en mucho mayor medida que al del consumo social de energía. El análisis del consumo eléctrico promedio por usuario, según entidades federativas, corrobora la relevancia del norte mexicano en términos de su mayor intensidad relativa. Los estados de Sonora, Coahuila, Nuevo León, Baja California Sur y Baja California, encabezan la jerarquía de entidades acorde con este parámetro. Sin embargo, el indicador diluye considerablemente la ponderación efectiva del usuario residencial en la medida que considera también usuarios que utilizan la energía como insumo productivo.

Considerando de manera específica la demanda social al examinar el comportamiento del consumo eléctrico residencial en zonas cálidas, los valores observados enfatizan claramente, no sólo la preeminencia de los estados norteños, sino particularmente, la singularidad de Baja California en el contexto de los usuarios residenciales en el país.

A su vez, información complementaria permite constatar que los montos anuales de facturación por usuario correspondientes a climas extremadamente cálidos - aplicación de la tarifa 1D-, cuadruplican los valores observados por un usuario residencial promedio nacional. Destacan incluso notablemente sobre los correspondientes a usuarios del resto de las zonas cálidas del país (1A, 1B y 1C). 


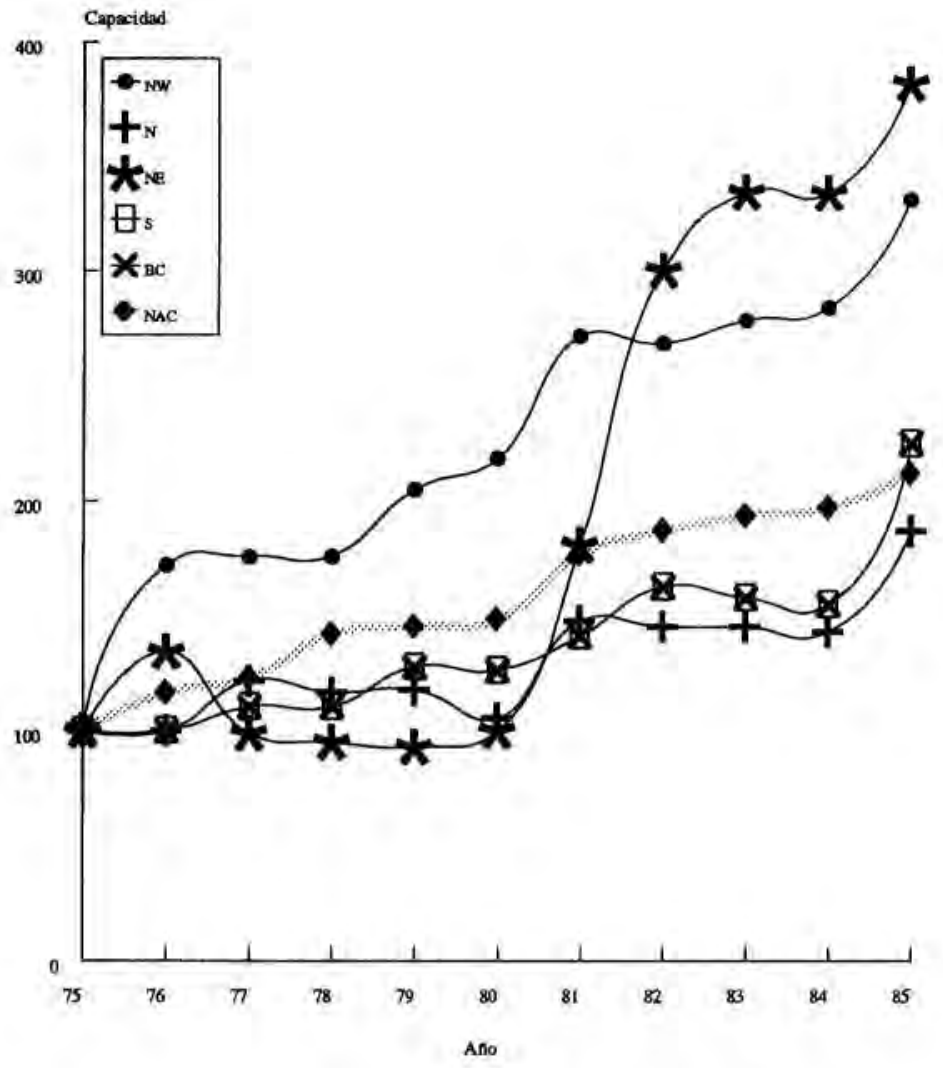

Figura 1. Capacidad instalada en el sector eléctrico. Crecimiento de sistemas interconectados.

Fuente: 10 años indicadores económicos. SPP. 1988. 
En ese sentido, información desagregada a escala subregional en el estado confirma la especificidad de Mexicali. En éste, el comportamiento del consumo eléctrico residencial, comercial e industrial revela el único patrón en que, además de rebasar ampliamente en su nivel absoluto al de los otros municipios, es el único en que el consumo residencial destaca sobre el industrial como componente de la demanda de energía eléctrica.

\section{CUADRO 1. Jerarquía del consumo eléctrico por usuario según entidad federativa (1990).}

\begin{tabular}{llrrr}
\hline Estado & & $\begin{array}{r}\text { Usuarios } \\
\text { Total }\end{array}$ & $\begin{array}{r}\text { Consumo } \\
\text { Total }(\mathrm{GWh})\end{array}$ & $\begin{array}{r}\text { Consumo/Usuario } \\
\text { (MWh/Usua) }\end{array}$ \\
\hline 1 Sonora & SON. & 428352 & 5436 & 12.69 \\
2 Coahuila & COA. & 444887 & 4310 & 9.69 \\
3 Nuevo León & N.L. & 737031 & 6976 & 9.47 \\
4 Baja California Sur & BCS & 71870 & 676 & 9.41 \\
5 Baja California & B.C.N. & 435986 & 3538 & 8.11 \\
6 Querétaro & QRO. & 188023 & 1488 & 7.91 \\
7 Quintana Roo & Q.R. & 110198 & 830 & 7.53 \\
8 Veracruz & VER. & 1010962 & 7606 & 7.52 \\
9 Chihuahua & CHI. & 557161 & 4112 & 7.38 \\
10 Tamaulipas & TAM. & 490877 & 3433 & 6.99 \\
11 San Luis Potosi & S.L.P. & 340467 & 2348 & 6.90 \\
12 Colima & COL. & 106499 & 728 & 6.84 \\
13 Aguascalientes & AGS. & 15540 & 9899 & 5.78 \\
14 Guanajuato & GTO. & 722477 & 4076 & 5.64 \\
15 Durango & DGO. & 256318 & 1429 & 5.58 \\
16 México & MEX. & 1740543 & 9576 & 5.50 \\
17 Hidalgo & HGO. & 316540 & 1721 & 5.44 \\
18 Puebla & PUE. & 677610 & 3474 & 5.13 \\
19 Distrito Federal & D.F. & 2153455 & 10146 & 4.71 \\
20 Jalisco & JAL. & 1182877 & 5516 & 4.66 \\
21 Sinaloa & SIN. & 449936 & 2098 & 4.66 \\
22 Zacatecas & ZAC. & 259644 & 1082 & 4.17 \\
23 Tabasco & TAB. & 284934 & 1171 & 4.11 \\
24 Tlaxcala & TLX. & 147030 & 574 & 3.90 \\
25 Michoacán & MIC. & 723517 & 2769 & 3.83 \\
26 Yucatán & YUC. & 318725 & 1129 & 3.54 \\
27 Morelos & MOR. & 278136 & 912 & 3.28 \\
28 Campeche & CAM. & 108290 & 349 & 3.22 \\
29 Guerrero & GRO. & 410562 & 1255 & 3.06 \\
30 Oaxaca & OAX. & 539529 & 1235 & 2.29 \\
31 Nayarit & NAY. & 187449 & 399 & 2.13 \\
32 Chiapas & CHA. & 450208 & 832 & 1.85 \\
Total & & 16285502 & 92123 & 5.66 \\
\hline & & & & \\
\hline
\end{tabular}

Fuente: Estadisticas por entidad federativa, CFE (1991). 


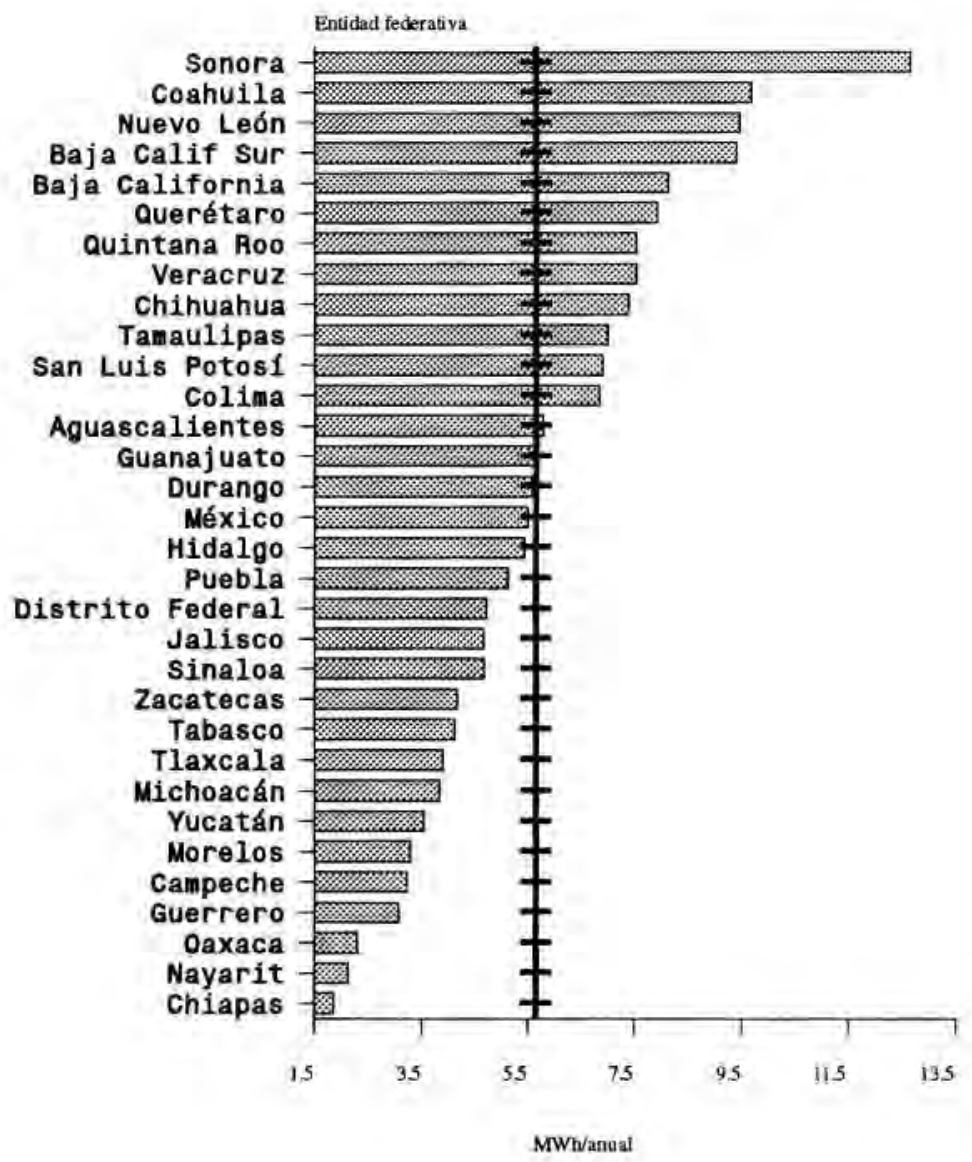

Figura 2. Consumo eléctrico por usuario (1990). Según entidad federativa.

Fuente: Estadísticas por entidad federativa, CFE, 1991. 


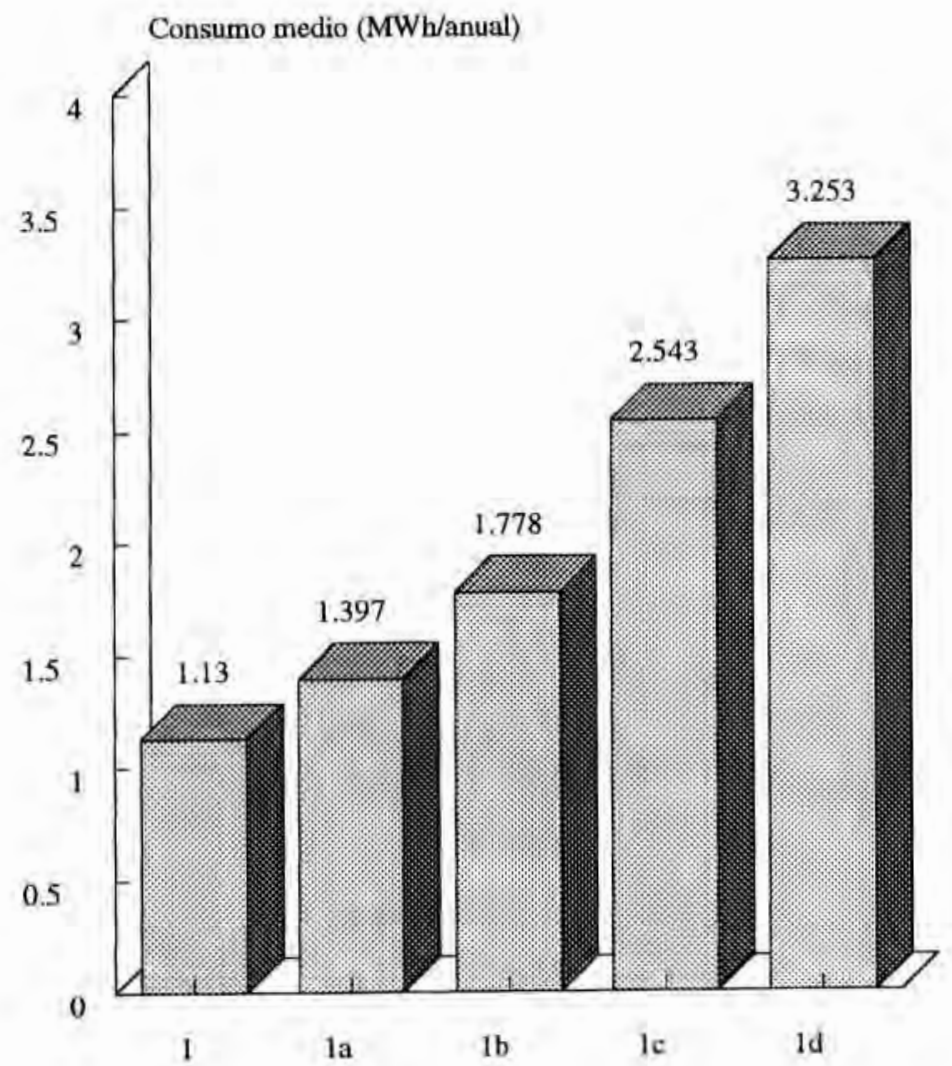

Tipo de usuario

Figura 3. Consumo promedio por usuario. Usuarios en climas cálidos (1990).

Fuente: Estadisticas por entidad federativa, CFE, 1991. 


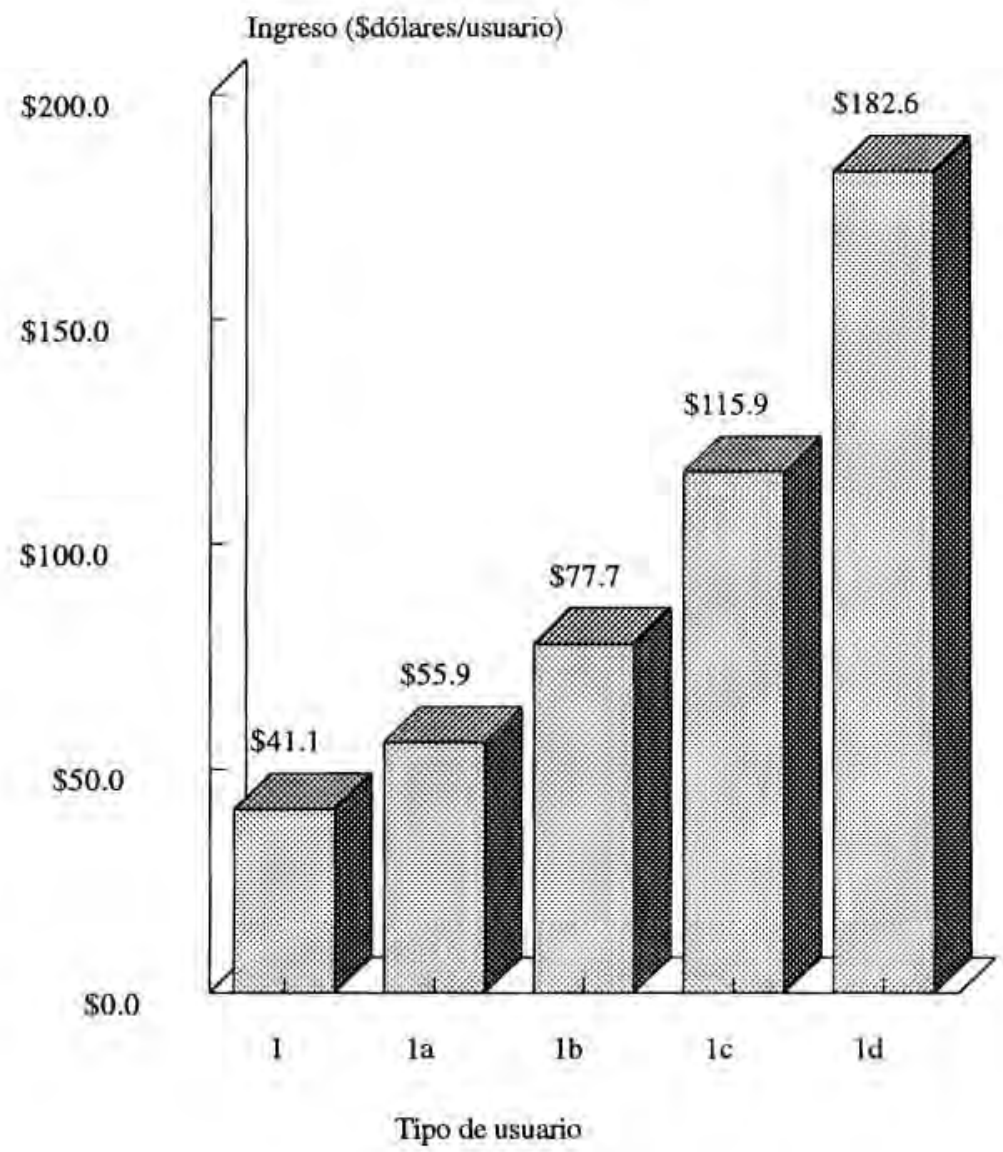

Figura 4. Facturación media anual por usuario. Usuarios en climas cálidos (1990).

Fuente: Estadisticas por entidad federativa, CFE, 1991 , 
CUADRO 2. Sector eléctrico nacional. Número de usuarios,
consumo y facturación (1990).

\begin{tabular}{lrrrrrrr}
\hline Tipo de Servicio & Usuarios & $\begin{array}{c}\text { Consumo } \\
\text { GWh }\end{array}$ & $\begin{array}{c}\text { Ingresos } \\
\text { SUSmmd }\end{array}$ & $\begin{array}{r}\text { Cons Prom } \\
\text { MWh/Usua }\end{array}$ & $\begin{array}{r}\text { Prec prom } \\
\text { SUS/kwh }\end{array}$ & $\begin{array}{r}\text { Ingr Prom } \\
\text { sUS/Usua }\end{array}$ \\
\hline 1Residencial & 8681174 & 9,808 & 356.5 & 1.1 & 0.04 & 41.1 \\
Ia Residencial cálido 1 & 1879461 & 2,626 & 105.0 & 1.4 & 0.04 & 55.9 \\
Ib Residencial cálido 2 & 2263705 & 4,024 & 176.0 & 1.8 & 0.04 & 77.7 \\
Ic Residencial cálido 3 & 1283844 & 3,265 & 148.8 & 2.5 & 0.05 & 115.9 \\
1d Residencial cálido 4 & 208705 & 679 & 38.1 & 3.3 & 0.06 & 182.6 \\
Exportación & & 1,946 & 86.5 & & & \\
\hline
\end{tabular}

Fuente: Estadisticas por Entidad Federativa, CFE, 1991.

Nota: GWh gigawatt-bora; \$USmmd millones de dólares; MWb megawatt-hora; kwh kilowatt-hora.

CUADRO 3, Cambios en el consumo nacional, usuarios y consumo unitario (1982-1990).

\begin{tabular}{|c|c|c|c|c|c|c|c|c|c|}
\hline & \multicolumn{2}{|c|}{1982} & \multicolumn{2}{|c|}{1990} & \multirow{2}{*}{$\begin{array}{c}1982 \\
\mathrm{C} / \mathrm{U}\end{array}$} & \multirow{2}{*}{$\begin{array}{c}1990 \\
\mathrm{C} / \mathrm{U}\end{array}$} & \multirow{2}{*}{\multicolumn{2}{|c|}{$\begin{array}{cc} & \text { TCPA } \\
\text { C } & \text { U }\end{array}$}} & \multirow[b]{2}{*}{$\mathrm{C} / \mathrm{U}$} \\
\hline & Usuarios & Consumo & Usuarios & Consumo & & & & & \\
\hline \multicolumn{10}{|l|}{ Nacional } \\
\hline Total1 & 1063802 & 61457 & 16285502 & 92123 & 5.55 & 5.66 & 5,19 & 4.95 & 0.23 \\
\hline Industrial & 37090 & 18691 & 111008 & 28326 & 503.94 & 255.17 & 5.33 & 14.69 & -8.15 \\
\hline Residencial & 9611133 & 12501 & 14313889 & 20400 & 1.30 & 1.43 & 6.31 & 5.10 & 1.15 \\
\hline Resid (1) & 6139203 & 6340 & 8681174 & 9809 & 1.03 & 1.13 & 5.61 & 4.43 & 1.13 \\
\hline Resid (ABCD) & 3471930 & 6161 & 5635715 & 10591 & 1.77 & 1.88 & 7.01 & 6.24 & 0.72 \\
\hline \multicolumn{10}{|c|}{ Estados norteños } \\
\hline Total & 2113620 & 17601 & 3094300 & 30505 & 8.33 & 9.86 & 7.12 & 4.88 & 2.13 \\
\hline Industrial & 12390 & 4670 & 39627 & 8661 & 376.92 & 218.56 & 8.03 & 15.64 & -6.59 \\
\hline Residencial & 1851917 & 3926 & 2612720 & 6442 & 2.12 & 2.47 & 6.39 & 4.40 & 1.91 \\
\hline Resid (1) & 280680 & 378 & 451424 & 744 & 1.35 & 1.65 & 8.83 & 6.12 & 2.56 \\
\hline Resid (ABCD) & 1571237 & 3548 & 2161296 & 5698 & 2.26 & 2.64 & 6.10 & 4.07 & 1.95 \\
\hline \multicolumn{10}{|c|}{ Baja California } \\
\hline Total & 287125 & 1781 & 435986 & 3538 & 6.20 & 8.11 & 8.96 & 5.36 & 3.42 \\
\hline Industrial & 788 & 445 & 3539 & 1066 & 564.72 & 301.22 & 11.54 & 20.65 & -7.56 \\
\hline Residencial & 51652 & 710 & 384961 & 1307 & 2.82 & 3.40 & 7.93 & 5.46 & 2.34 \\
\hline Resid (1) & I 45402 & 248 & 231350 & 501 & 1.71 & 2.17 & 9.19 & 5.98 & 3.03 \\
\hline Resid (ABCD) & 106250 & 462 & 153611 & 806 & 4.35 & 5.25 & 7.20 & 4.72 & 2.38 \\
\hline
\end{tabular}

Fuente: Estadisticas por Entidad Federativa, CFE, 1991.

Nota: Consumo en GWh y consumo por usuario (C/U) en MWh; Resid (ABCD) tarifas zonas cálidas. 


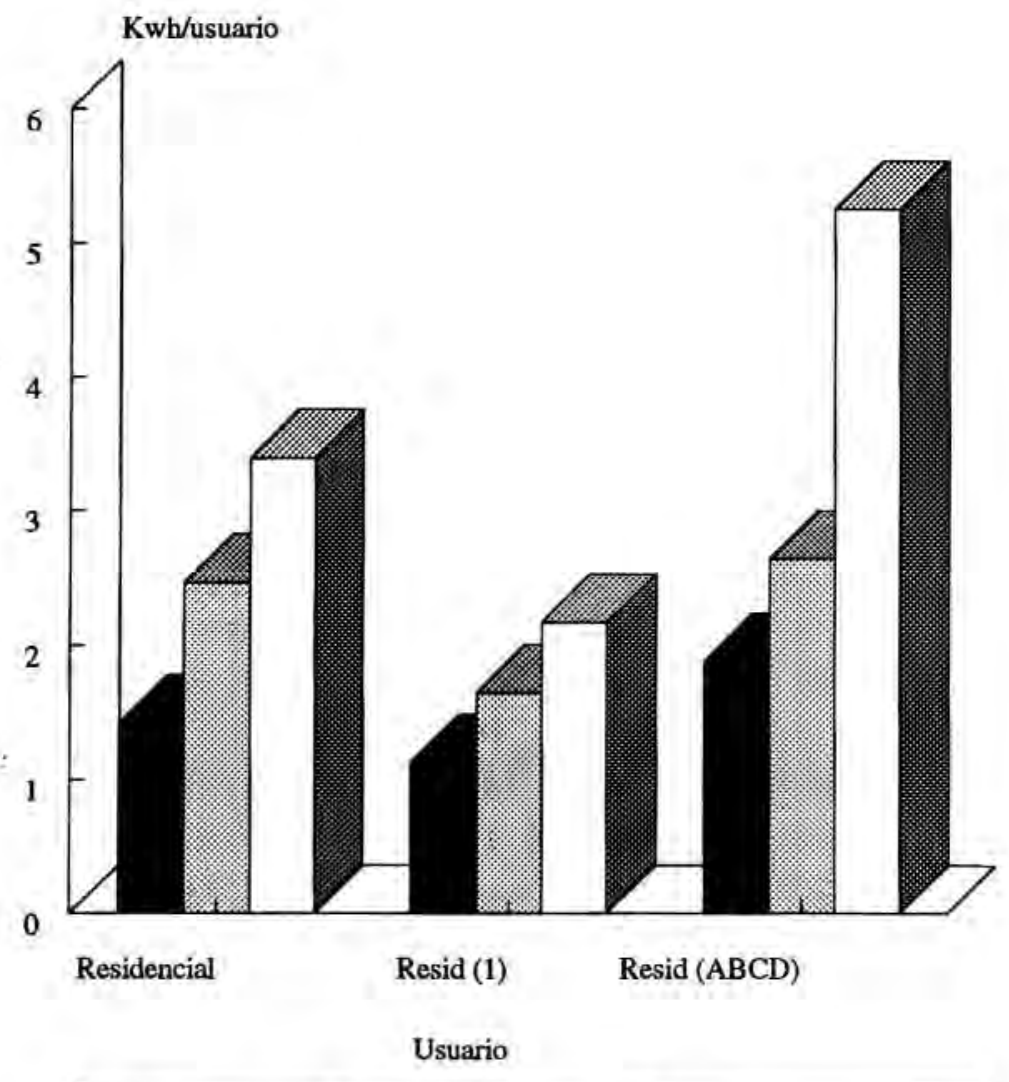

$\square_{\text {Nadional }} \quad \square_{\text {Baja Califormia }}$

Figura 5. Consumo por tipo de usuario residencial. Nacional, estados del norte, Baja California.

Fuente: Estadísticas por entidad federativa, CFE, 1991. 
CUADRO 4. Consumo de energía eléctrica (MWh) en Baja California (1991).

\begin{tabular}{|c|c|c|c|c|c|}
\hline Sectores & Tijuana & Tecate & Ensenada & Mexicali & Total \\
\hline Doméstico (T1) & $2,524,375$ & 145,194 & 712,373 & $4,619,630$ & $8,001,572$ \\
\hline Comercial (T2-T3) & $1,454,090$ & 85,161 & 339,267 & $1,282,378$ & $3,160,896$ \\
\hline Industrial (T8-T12) & $3,837,179$ & 237,284 & $1,120,167$ & $4,201,938$ & $9,396,568$ \\
\hline Agricola (T9) & 11,889 & 17,346 & 286,464 & 588,533 & 904,232 \\
\hline Alumbrado público & 138,934 & 14,271 & 74,511 & 121,692 & 349,408 \\
\hline Temporal (TT) & 790 & & 524 & & 1,314 \\
\hline Molinos (T4) & 84 & & 68 & 950 & 1,102 \\
\hline Bombeo (T6) & 112,571 & 13,001 & 47,867 & 188,993 & 362,432 \\
\hline TOTAL & $8,079,912$ & 512,257 & $2,581,241$ & $11,004,114$ & $22,177,524$ \\
\hline Usuarios & 184,703 & 11,571 & 58,033 & 163,967 & 418,274 \\
\hline Consumos/usuario & Tijuana & Tecate & Ensenada & Mexicali & Total \\
\hline Doméstico (T1) & 13.67 & 12.55 & 12.28 & 28.17 & 19.13 \\
\hline Comercial (T2-T3) & 7.87 & 7.36 & 5.85 & 7.82 & 7.56 \\
\hline Industrial (T8-T12) & 20.77 & 20.51 & 19.30 & 25.63 & 22.47 \\
\hline Agrícola (T9) & 0.06 & 1.50 & 4.94 & 3.59 & 2.16 \\
\hline Alumbrado público & 0.75 & 1.23 & 1.28 & 0.74 & 0.84 \\
\hline Temporal (T7) & 0.00 & 0.00 & 0.01 & 0.00 & 0.00 \\
\hline Molinos (T4) & 0.00 & 0.00 & 0.00 & 0.01 & 0.00 \\
\hline Bombeo (T6) & 0.61 & 1.12 & 0.82 & 1.15 & 0.87 \\
\hline TOTAL & 43.75 & 44.27 & 44.48 & 67.11 & 53.02 \\
\hline
\end{tabular}

Fuente: Estadísticas básicas de Baja California. Secretaría de Desarrollo Económico (1992).

El conjunto de observaciones anteriones muestra no solo la naturaleza crítica y heterogénea del universo de usuarios residenciales en zonas cálidas sino, al interior de ese universo, la notable especificidad en la situación de Baja Califomia y del municipio de Mexicali en el contexto del noroeste mexicano. 


\section{El valle de Mexicali, Baja California}

La potencialidad de la gestación de toda una problemática social derivada de las necesidades de consumo eléctrico, tiene en nuestra región una base geográfica y un origen histórico. La colonización del valle de Mexicali, a principios de este siglo, registra testimonios diversos que apuntan el problema de las altas temperaturas como nítido elemento de su especificidad.

El surgimiento de Mexicali como centro de población, bajo las condiciones naturales y geoeconómicas más adversas, constituye un hecho histórico que explica el reconocimiento que actualmente se guarda hacia los pioneros colonizadores de la región.

Durante décadas, el auge económico y nivel relativo de bienestar experimentado en la región, impidieron que el gasto energético derivado de las necesidades de acondicionamiento térmico para la vivienda y las edificaciones en la temporada de verano fuese considerado como un problema.

Facilidades para la importación de equipos, paralelas al comportamiento favorable de la actividad y el ingreso regional a lo largo de varias décadas, desvanecieron la preocupación de la población y el interés de los constructores en utilizar criterios de adecuación ambiental en la edificación de viviendas.

Durante la década de los ochenta, la drástica contracción en los ingresos familiares, particularmente de la población fronteriza -que recibe adicionalmente el impacto de las fases subvaluatorias en el manejo del tipo de cambio-, ha significado un duro golpe al bienestar social general. Un sustancial cambio en los patrones de consumo fronterizo a raíz de la crisis ha permitido que la cuestión del consumo eléctrico junto con los costos de urbanización, el transporte urbano, el uso del agua, etcétera, cobren importancia fundamental.

En el contexto particular de Mexicali, el gasto familiar destinado al pago de la energía eléctrica ha competido con otros satisfactores básicos en un decreciente presupuesto familiar.

Los acuerdos tarifarios para determinar el precio de la electricidad de fines de los ochenta, encontraron una considerable caja de resonancia en la población mexicalense. Cada nueva disposición enfrenta esta atmósfera social inercialmente adversa, de manera cíclica y explosiva, manifestándose con mayor fuerza cada verano. La permanencia e insuficiencia del subsidio puede traducirse en un reconocimiento implícito de la complejidad del problema. 
CONTEXTO DE LA POLITICA TARIFARIA RESIDENCIAL

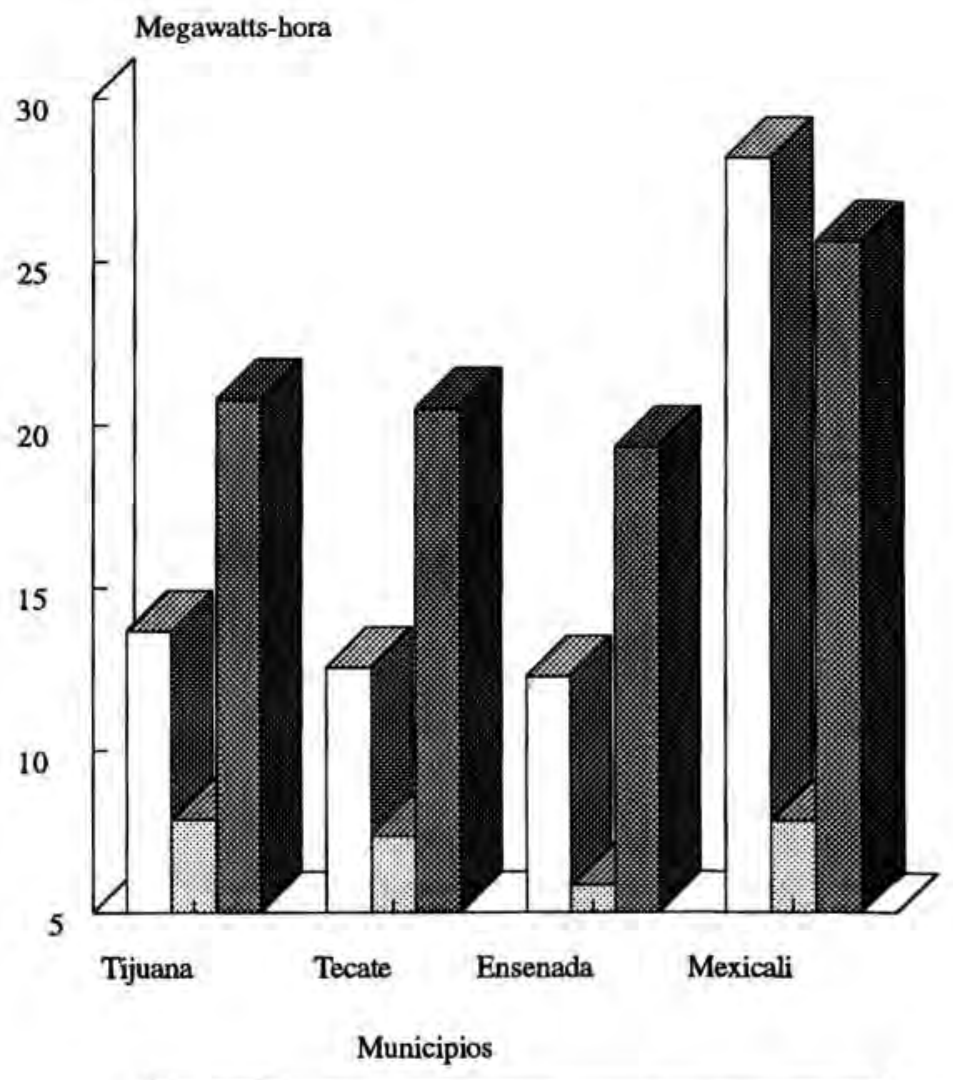

$\square_{\text {Residencial }} \quad$ Comercial

Figura 6. Consumo eléctrico entre usuarios totales, Baja California, 1990.

Fuente: Estadisticas básicas de Baja California, Secretaría de Desarrollo, 1992. 


\section{Condiciones del medio natural}

El valle de Mexicali se sitúa en el norte de la península de Baja California, en el delta del Río Colorado, colinda al norte con el Valle Imperial en California, al oeste con la sierra de Juárez, al este con el mar de Cortez y al sur con otros valles bajacalifornianos.

La región del valle de Mexicali cuenta con un clima seco, desértico, de los más extremosos en México. Tiene una precipitación pluvial de $74 \mathrm{~mm}$ al año. Sus variantes climáticas se suceden entre 39 a 40.8 grados centígrados promedio máximas en verano y de 5 a 7 grados promedio mínimas en invierno. Anualmente las variaciones registran una mayor duracion de las temporadas de máximas temperaturas en comparación con las bajas. Durante seis meses del año el clima es caluroso y específicamente en tres meses - julio, agosto y septiembre- se dan las temperaturas más altas, las cuales en días de calor extremo, registran niveles de 48.8 grados centígrados.

En diciembre y enero se presentan temporadas frías que observan descensos del orden de -2 grados centígrados. Sin embargo, la probabilidad de nevadas es mínima, considerando la localización del valle rodeado de sierras y desierto. Además, dado el ángulo de incidencia de los rayos solares, el inviemo ofrece una notable ganancia de calor para la vivienda promedio.

Lo anterior indica que aun tratándose de una región de clima extremoso, el problema se ubica casi exclusivamente en la temporada de verano, situación que contrasta con el problema de las regiones de clima extremoso en Califomia donde las temporadas frías son igualmente importantes.

Las condiciones climáticas extremas en la región, imponen mayores estándares de consumo eléctrico para alcanzar niveles de confort socialmente aceptables. Sin embargo, a partir de fines de los ochenta, el impacto económico asociado a estos parámetros de consumo, ba reducido drásti. camente el bienestar de un amplio sector de la población.

\section{Entorno socioeconómico}

La región del valle de Mexicali reúne en su mayor centro de población, la ciudad de Mexicali, a más de 130000 hogares. Sus principales actividades son el comercio, los servicios, la industria y la agricultura. El nivel adquisitivo promedio, al igual que en otras zonas del país, se contrajo durante la década de los ochenta más de cincuenta por ciento.

En cuarenta por ciento de los hogares trabaja más de uno de sus miembros, revelando la creciente insuficiencia de un salario para proveer 
de los bienes y servicios requeridos para el sostenimiento del hogar (UABC-Instituto de Investigaciones Sociales, CFE, XII Ayuntamiento de Mexicali, 1990: ver punto 1.4). La interacción económica con el exterior es significativa: uno de cada diez jefes de familia se vincula con los Estados Unidos, ya sea trabajando actualmente $\mathbf{u}$ obteniendo algunos ingresos provenientes de este país.

La distribución personal del ingreso entre jefes de hogar, revela un comportamiento asimétrico respecto a su nivel promedio, en el que resulta muy destacada la presencia de aquéllos que obtienen ingresos que van de 1.5 a 3.5 veces el salario mínimo, representando cerca de $45 \%$ de las personas que se encuentran al frente de un hogar.

Considerando la distribución familiar del ingreso, el comportamiento se vuelve ligeramente más simétrico, pasando a concentrarse en niveles que van de dos a cinco salarios mínimos. Sin embargo, la proporción de hogares que subsisten con ingresos menores a dos salarios mínimos es casi uno de cada tres, lo cual es bastante significativo.

Debido a las condiciones del medio natural, de la notable inadecuación ambiental de la vivienda y la contracción del ingreso familiar, la facturación local por consumo eléctrico - tanto en su monto absoluto como relativo-, resulta más elevada que en cualquier ciudad del país.

El concepto de confort incluye el mantenimiento de condiciones medias aceptables de temperatura ambiente en la vivienda; su estudio integral hace necesario un análisis de la capacidad instalada en equipo para el acondicionamiento térmico en la vivienda así como de su diseño, toda vez que este factor altera la relación entre consumo de energía y confort.

En relación al bienestar en términos de ingresos familiares, puede establecerse una proporción típica de gasto destinado al consumo eléctrico en el país. En México, este dato se ha mantenido cercano a 3\% (SPP, 1979). Tomando en cuenta este parámetro, se procede a estimar su valor correspondiente para distintos grupos de ingreso en la región como forma de aproximar la evaluación de su impacto social.

\section{Consumo y facturación de energía eléctrica}

Las encuestas realizadas en 1989 y 1990 confirman una marcada elevación del. promedio social de consumo eléctrico durante el verano. A partir del mes de mayo, se inicia un ascenso en el consumo que alcanza un máximo durante agosto y septiembre para lograr descensos significativos después de octubre. Mientras en el verano el nivel promedio fluctúa entre los 700 y $1000 \mathrm{kwh}$, el resto del año lo hace entre 200 y $300 \mathrm{kwh}$ (ver cuadro 5). 
CUADRO 5. Mexicali, B.C. Promedios de consumo eléctrico (kwh) según ingresos mensuales familiares (1989).

\begin{tabular}{lllllllllllll}
\hline & \multicolumn{10}{c}{ Veces salario mínimo } \\
Mes & Gral. & -1 & -1.5 & -2 & -3.5 & -5 & -6.5 & -8 & -9.5 & -11 & +11 \\
\hline Enero & 252 & 241 & 233 & 215 & 234 & 263 & 269 & 272 & 261 & 254 & 346 \\
Febrero & 224 & 192 & 196 & 188 & 213 & 243 & 229 & 245 & 227 & 220 & 306 \\
Marzo & 230 & 199 & 193 & 193 & 200 & 282 & 230 & 242 & 225 & 212 & 323 \\
Abril & 260 & 242 & 247 & 212 & 247 & 295 & 267 & 248 & 275 & 254 & 354 \\
Mayo & 359 & 310 & 313 & 304 & 333 & 387 & 354 & 358 & 497 & 407 & 473 \\
Junio & 446 & 407 & 370 & 340 & 404 & 480 & 457 & 478 & 515 & 604 & 709 \\
Julio & 653 & 554 & 548 & 473 & 582 & 780 & 706 & 691 & 730 & 828 & 891 \\
Agosto & 747 & 685 & 582 & 605 & 685 & 821 & 852 & 817 & 810 & 887 & 953 \\
Septiembre & 697 & 634 & 552 & 499 & 617 & 786 & 784 & 743 & 808 & 865 & 1072 \\
Octubre & 534 & 514 & 404 & 378 & 469 & 577 & 658 & 601 & 632 & 638 & 778 \\
Noviembre & 303 & 286 & 264 & 250 & 272 & 319 & 326 & 343 & 308 & 358 & 442 \\
Diciembre & 237 & 234 & 213 & 204 & 218 & 251 & 244 & 256 & 248 & 298 & 325 \\
\hline
\end{tabular}

Fuente: UABC-IIS, CFE, XIII Ayuntamiento de Mexicali (1990).

Nota: - Rango respecto al valor anterior.

+ Rango a partir del valor indicado.

A pesar de que durante el verano ha operado un subsidio para usuarios ubicados en los rangos de menor consumo, el comportamiento del importe promedio mensual (facturación) obtenido de las encuestas, nos revela que el desembolso sigue concentrándose notablemente en los meses más calurosos. La aplicación del subsidio en el verano no alcanza a suavizar los efectos derivados de las necesidades de consumo en esta temporada.

Al analizar la información de EAAVCE (1990) de acuerdo con los diferentes niveles de ingreso familiar, se aprecian diferencias significativas en el consumo promedio a lo largo de todo el año. Esta diferencia alcanza un máximo precisamente cuando consideramos índices de consumo correspondiente al verano.

En términos absolutos, son mayores los montos facturados por usuarios de mayores niveles de ingreso familiar, aunque ello no signifique necesariamente que en ellos se observe un impacto social mayor si ponderamos suficientemente la desigualdad que prevalece entre estratos de ingreso. 
De la misma manera también pudo probarse que aquellos hogares en los que el jefe tiene actividades laborales o ingresos provenientes de los Estados Unidos, no se colocan entre aquellos usuarios que hacen mayores usos del servicio en sus hogares.

De acuerdo con información proporcionada por ambas encuestas, existe una notable regresividad en la forma en que la estructura tarifaria afecta a los diferentes grupos sociales. En estratos de menor consumo de energía se aprecia un sensible predominio de usuarios con menor nivel de ingreso.

Por ejemplo, de acuerdo con la encuesta de 1990, entre los 200 y 500 $\mathrm{kwb}$ en verano, seis de cada diez hogares tienen ingresos menores a tres y media veces el salario mínimo. Pero entre los 1500 y $2000 \mathrm{kwh}$, más de la mitad de los hogares tienen ingresos mayores a dicho nivel.

Aunque exista correlación entre consumo eléctrico e ingreso familiar, su grado de asociación no es muy alto, Ello muestra que el ingreso familiar es significativo aunque no es el factor determinante en la explicación del consumo observado en un hogar.

Existen diferencias significativas en el impacto según el estrato de consumo. A partir de $20 \%$ de impacto en el gasto familiar, la presencia de consumidores que registran entre 1500 y $2000 \mathrm{kwh}$ deja de ser importante.

En ocho de cada diez hogares, la proporción media anual destinada al pago de la energía eléctrica en el gasto familiar fue de hasta $10 \%$, es decir, tres veces más que el parámetro medio a nivel nacional. Sin embargo, los hogares de más de ocho veces salario mínimo, no destinaron al pago de energía, en promedio, más de $2 \%$ de sus ingresos. Al mismo tiempo, los hogares de menores ingresos - menos de dos veces el salario mínimo-. destinaron aproximadamente, en promedio, entre 8.7 y $18 \%$ de sus percepciones anuales.

El indicador se vuelve más nítido si atendemos a su comportamiento estacional. En el periodo de verano, aunque el nivel promedio parece elevarse poco, su distribución resulta mucho más asimétrica, pues comprende desde menos de dos $2 \%$ para los hogares de mayores ingresos y más de 20\% para los de menores. Desagregando los promedios, encontramos que al interior del conjunto de familias con ingreso menor a dos veces el mínimo, casi uno de cada cinco llegó a destinar más de $40 \%$ de sus percepciones al pago por este servicio.

En general, el examen del consumo de energía durante el periodo de verano, revela un esfuerzo considerable de la población contrayendo significativamente su confort a cambio de no impactar más drásticamente su gasto familiar. 
CUADRO 6. Mexicali, B.C. Incidencia media del consumo eléctrico (1989) según ingresos familiares (porcentaje).

\begin{tabular}{lrrrrr}
\hline Ingreso familiar & Anual & Verano & Julio & Agosto & Septiembre \\
\hline Menos de 1 vSM & 18.4 & 19.4 & 20.3 & 23.3 & 20.2 \\
1 - 1.5 vSM & 9.3 & 9.8 & 10.3 & 11.1 & 10.4 \\
$1.5-2$ vSM & 6.7 & 7.0 & 7.2 & 8.8 & 6.9 \\
2 - 3.5 vSM & 5.0 & 5.6 & 6.0 & 6.3 & 5.9 \\
$3.5-5$ vSM & 4.3 & 4.8 & 5.4 & 5.4 & 5.4 \\
$5-6.5$ vSM & 3.1 & 3.4 & 3.5 & 4.0 & 3.7 \\
$6.5-8$ vSM & 2.6 & 2.9 & 3.2 & 3.2 & 3.1 \\
$8-9.5$ vSM & 2.2 & 2.7 & 2.9 & 3.1 & 3.1 \\
$9.5-11$ vSM & 2.0 & 2.1 & 2.4 & 2.6 & 2.2 \\
Más de 11 vSM & 1.7 & 1.9 & 1.8 & 1.9 & 3.1 \\
TOTAL & 4.8 & 5.3 & 5.7 & 6.2 & 5.7 \\
\hline
\end{tabular}

Fuente: IS/UABC, CFE, XII Ayuntamiento, 1990.

VSM: veces salario mínimo

\section{Estudio de la demanda eléctrica residencial}

En 1990, el Instituto de Investigaciones Sociales de la Universidad Autónoma de Baja California, llevó a cabo la "Encuesta sobre adecuación ambiental de la vivienda y consumo eléctríco en Mexicali, B.C." (EAAVCE) mediante convenio establecido con el H. XIII Ayuntamiento de Mexicali y contando con la colaboración de Comisión Federal de Electricidad, con una importante aportación de datos, así como recursos materiales y humanos en la realización de estas tareas. El convenio estableció condiciones para publicación de los resultados, así como la promoción de los mismos para el desarrollo de programas de beneficio comunitario.

En virtud de la colaboración formalizada en el convenio pudo generarse una base de datos que posibilita el examen de determinantes sociales y de adecuación ambiental de la vivienda en el modelo de consumo eléctrico residencial. Ello permite establecer condiciones que matizan considerablemente una política social de adecuación ambiental de la vivienda orientada a fortalecer el bienestar comunitario en diversas formas.

El objetivo general del proyecto es la obtención de un modelo para el estudio de la demanda eléctrica residencial, facilitando la estimación de efectos inducidos en su perfil, agregado ante modificaciones en las políticas de ahorro de energía, como las ahora vigentes en la región. 
Como objetivos específicos se enumeran tres principales:

a) Obtención de un instrumento analítico útil en la estimación de los efectos derivados del manejo de alternativas, tales como programa de aislamiento de viviendas, plan IDEAA, etcétera;

b) Modelación de comportamientos de consumo a partir de la base de datos del proyecto EAAVCE realizado durante 1990 mediante convenio entre Instituto de Investigaciones Sociales y XII Ayuntamiento de Mexicali;

c) Evaluación de impacto financiero en alternativas de diseño subsidiario, determinando montos económicos según estratificación de usuarios, así como de las elasticidades de la demanda de consumo eléctrico.

\section{CONTEXTO ACTUAL DE LAS POLÍTICAS EN EL SECTOR ELÉCTRICO}

\section{La energía en la agenda mundial de los noventa}

La demanda mundial de petróleo aumenta nuevamente. El empleo de carbón y energía nuclear enfrentan obstáculos cada vez mayores, mientras concomitantemente, consideraciones ambientales aumentan la presión que afecta al sistema de suministro de energía.

Existe incertidumbre acerca de la conducción de los mercados energéticos en los noventa (Yergin, 1989). Ello incluye tanto el monto de los suministros no provenientes de la OPEP como el crecimiento económico de países industrializados y no industrializados. El petróleo es la fuente de energía más importante por amplio margen. En el ramo de transporte, no cuenta con sustituto disponible. A nivel mundial, la mayor parte de las reservas probadas se encuentran lejos de los más importantes consumidores.

Sin embargo, no sólo en materia de hidrocarburos surgen problemas. En la industria eléctrica existe preocupación de que en el futuro algún desastre nuclear suscite más presiones políticas para desconectar la energía nuclear. La preocupación por problemas ambientales relativos al efecto de invernadero y a la elevación de la temperatura planetaria podría dirigirse a un acelerado alejamiento de los combustibles fósiles. (Yergin, 1989:18).

La crisis energética de principios de los setenta impulsó políticas de conservación y ahorro que tuvieron gran impacto en el consumo mundial. Se llegó a sostener que, a fines de la década, Estados Unidos podría emplear entre $30 \%$ y $40 \%$ menos energía por unidad del PNB de lo que empleaba en 1973, con escasos o nulos efectos en el nivel de vida. Conservación y ahorro se convierten en fuente importante de incremento de energía. 
Posteriormente, Estados Unidos establece una reserva estratégica de petroleo que comprende alrededor de 550 millones de barriles, con cobertura de 92 días de abastecimiento del nivel de importación actual (Yergin, 1989:20).

La capacidad de los equipos de combustión en plantas generadoras de energía e industrias fabriles para su adaptación y funcionamiento con gas o carbón en vez de petróleo, extiende su uso mucho más a partir de 1973. Esta capacidad proporciona al consumidor industrial acceso a una fuente de energía barata.

Sin embargo, los bajos precios por barril de petróleo en épocas recientes han conducido a consumos superiores a los prevalecientes a que si el precio fuese mayor. Datos de fines de los ochenta, indican que ha disminuido relativamente el esfuerzo de conservación.

Las posibilidades en materia de fuentes adicionales de abastecimiento en un ambiente predominantemente de bajos precios serían:

a) Gas: presenta ventajas para la atmósfera y clima; su desventaja está en el costo de transporte a grandes distancias.

b) Carbón: aumenta mucho su participación en el mercado en la generación de electricidad y se beneficia con el estancamiento de la energía nuclear.

c) Energía nuclear: continuamente reduce sus planes de expansión.

La preocupación por el aumento de la temperatura en el mundo estimula debates sobre el desarrollo de una nueva generación de reactores nucleares más pequeños y seguros.

Por su parte, el significativo descenso que registra la producción estadounidense de petróleo, (Yergin, 1989) subraya la importancia de los aumentos generalizados en países no pertenecientes a la OPEP. La disparidad entre la producción y reservas de petroleo parece sugerir que, a la larga, se habrá de apoyar de nuevo en las reservas de la OPEP y el Medio Oriente.

En materia de eficiencia, puede decirse que el aspecto de la conservación ha alcanzado un elevado nivel de aprobación y estima universal. Consideraciones ambientales, presiones al suministro eléctrico e introducción de tecnología en países en desarrollo, son factores que fundamentan y apoyan la importancia de una mayor eficiencia energética.

El capítulo energético se asocia cada más estrechamente con la problemática ambiental. Los temas relativos a producción y uso de energía alcanzan la mayor prominencia, ocupando un lugar sobresaliente dentro del asunto ambiental en la agenda política mundial (Fri, 1989:33). La perspectiva de un conflicto entre intereses energéticos y ambientales es perturbadora e inquieta cada vez más a los formuladores de las políticas. 
La necesidad energética para sostener el crecimiento económico de países en desarrollo, es precursora de posibles conflictos de intereses por habitar en ellos más de tres cuartas partes de la población mundial. Sin embargo, su consumo de energía per cápita es menos de la décima parte del que realiza la población en países desarrollados (Fri, 1989:33).

La interdependencia mundial entre energía y medio ambiente presenta grandes dilemas económicos y políticos. Es difícil proponer a países en desarrollo que se abstengan de poner en riesgo el ambiente cuando ello representa un retraso para salir de la pobreza. Asegurar la protección del ambiente junto al crecimiento económico podría imponerles costos inaceptables.

Estados Unidos parece evitar el conflicto de intereses haciendo que los costos de protección ambiental sean más o menos invisibles para la mayoría de su población. En general, sus políticas ambientales imponen costos a productores de bienes y servicios, que se traspasan a los consumidores en los precios.

La agencia de protección ambiental estadounidense (EPA), ha informado que el costo para poner en vigor sus reglamentaciones respecto a contaminación de aire y agua sobrepasa, en promedio, los 60000 millones de dólares anuales. Expertos de Recursos para el Futuro en la ciudad de Washington, D.C. sugieren que, analizando debidamente dicha estimación, inclusive podría estar por debajo de los verdaderos costos sociales (Fri, 1989:34).

En el futuro, la naturaleza de los problemas energéticos-ambientales no dejará tratar con imprecisión la cuestión del equilibrio entre beneficios y costos. A medida que el cada vez más grave efecto potencial de tales problemas haga transparentes los beneficios y costos de su manejo, resultará inevitable un equilibrio más explícito.

En forma parecida, es recomendable la descentralización en la toma de decisiones para lograr mayor eficiencia en la utilización de recursos que busque nuevas metas de política pública. Como regla general, se espera que la descentralización mejore la eficiencia, dado que un aumento en el número y en la libertad de los agentes económicos tiende a expandir la escala de opciones.

El principio de compensación debiera aplicarse cuando todas las partes participan en la solución de los problemas energético-ambientales. Aún bajo el supuesto de que el mundo desarrollado admite que la reduccion vale el costo que representa y está dispuesto a pagarlo, surge la cuestion de cómo lograr más efectivamente esta reducción.

No es posible esperar a que los países en desarrollo utilicen recursos propios para limitar sus emisiones de bióxido de carbono por el bien de la 
sociedad en general. Tampoco ayuda invocar el principio de que quien contamina es quien debe pagar. La equidad sugiere que si los países desarrollados desean fijar límites a las emisiones de bioxido de carbono, deben pagar por ello de alguna forma.

En su análisis del tema, Robert W. Fri (1989) afirma que los principios de equilibrio de beneficios y costos, descentralización de decisiones y compensación a perdedores, no son fáciles ni gratuitos de aplicar. Ello depende de instituciones y métodos que necesitan mejorarse y, en ocasiones, inventarse. No es tarea fácil, debido a que a las instituciones políticas y sociales existentes les incomodan estas ideas.

\section{Consumo de energía y estudios sociales}

El examen de los determinantes sociales en el consumo energético y sus repercusiones en el estilo de desarrollo, son hoy en día asuntos de la mayor relevancia para la fundamentación de múltiples acciones y programas, tanto del sector público como de los sectores privado y social. En particular, la consideración amplia de sus implicaciones tecnológicas, económicas y ambientales supone la regulación y diseño de políticas públicas necesariamente destinadas a propiciar usos racionales y eficientes del recurso energético.

Hacia fines de los setenta, a solicitud del Departamento de Energía, Agua y Telecomunicaciones del Banco Mundial a la organización Recursos para el Futuro de Washington, D.C., Cecelski, Dunkerley y Ramsay (1979) condujeron un estudio sobre necesidades energéticas y posibilidades para hogares de muy bajos ingresos en países en desarrollo. El énfasis fue sobre el consumo de energía - preparación de alimentos, calefaccion e iluminacion-, tanto de los hogares urbanos de muy bajo ingreso como de los rurales, así como de sus posibilidades de abastecimiento a través de tecnologías no convencionales.

Entre las conclusiones generales del estudio se estableció: uno, que la energía es utilizada con deficiencia en muchas partes del mundo en desarrollo; dos, que existe oportunidad de ahorro si la eficiencia se mejora; tres, que los factores culturales e institucionales son relevantes al cambiar tecnologías energéticas.

Varias razones comprendieron la justificación de dicho estudio. En primer lugar, que el aprovisionamiento de las necesidades energéticas del hogar representa una parte sustancial de los recursos en hogares de muy bajo ingreso, sea en dinero o en tiempo. En segundo, que en los menores niveles de ingreso la energía se utiliza casi exclusivamente para satisfacer necesidades humanas muy básicas - cualquier reducción en el consumo 
por debajo de este nivel puede conducir a una contracción de los estandares nutricionales y concomitantemente de la capacidad productiva.

Desde el punto de vista de las políticas públicas, el tópico resulta de la mayor importancia. El consumo residencial de energía representa la mayor parte del total de consumo de energía - cerca del 50\%- en países en desarrollo. Por otro lado, el mero aumento del ingreso para los sectores pobres no resuelve el problema. Algunos de los nuevos sistemas energéticos podrían incluso tener efectos negativos sobre la distribución del ingreso. Una política que enfatice en la provisión de necesidades básicas incrementaría tanto la demanda derivada de energía por el mayor ingreso como la energía incorporada en los servicios.

En el contexto de la pobreza, una comparación economica abstracta de oferta y demanda es un análisis incompleto. Factores culturales y de equidad aparecen particularmente significativos en la aplicación exitosa de programas de energía que impliquen nuevas fuentes energéticas.

Según el estudio de Recursos para el Futuro (Cecelski), la distribución del ingreso existente y los patrones de propiedad, condicionan el posible beneficio de nuevos sistemas para los hogares pobres. Inversiones que son económicas a largo plazo pueden no ser inicialmente asequibles a hogares de bajos ingresos. Se requiere mayor atencion al análisis de los pros y contras desde el punto de vista del costo social de créditos o subsidios que permitiesen a los hogares de bajos ingresos utilizar nuevas fuentes de energía.

Una forma directa de observar el efecto de cambios en el nivel de ingreso sobre el total de energía consumida, es el análisis de los patrones de consumo energético de diferentes estratos de ingreso dentro de la misma region o ciudad.

Algunos estudios (Cecelski) indican que el consumo doméstico de energía crece mucho menos que el ingreso, cuando menos entre los grupos de bajos recursos. Estimaciones para la ciudad de México indican un incremento muy gradual en el consumo residencial de energía entre los grupos de ingreso.

La cantidad de energía consumida por los hogares pobres es frecuentemente descrita en la literatura especializada como inelástica, en el sentido de tratarse de una necesidad básica que ha de proveerse en cualquier circunstancia. La hipotesis de inelasticidad tiene dos aspectos: implica que el consumo de energía no responde a cambios en los precios. Sin embargo, los datos parecen indicar cierta inelasticidad-ingreso de la demanda para muy bajos niveles de ingreso. Después de cierto nivel "umbral" de ingreso -más alto que el de los pobres urbanos o rurales-, puede darse un incremento preciso en el consumo residencial al tener acceso a nuevos 
servicios que utilizan electricidad. Los ingresos crecientes parecen conducir a sustituir los combustibles no comerciales por los comerciales.

En encuestas sobre el gasto en hogares, la relación entre consumo de energía e ingreso se mide en términos de valor. Estas encuestas, consistentemente indican que tanto en áreas urbanas como rurales el gasto en combustible y electricidad se incrementa con el ingreso, aunque menos rápidamente que aquél, es decir, el porcentaje destinado a la energía se reduce cuando el ingreso crece. Típicamente, en grupos de alto ingreso el gasto en combustible y electricidad significa cerca de 2 a $3 \%$ del gasto, pero en los rangos de ingreso más bajo, la proporción es sustancialmente mayor (el $10 \%$ es muy típico). En algunos países latinoamericanos la proporción se estima cercana al 5 u $8 \%$ (Cecelski).

En materia de diseño tarifario, el estudio establece que los precios de la energía explican parcialmente las diferencias en los niveles de consumo. La determinación de precios provee de un instrumento de política para inducir cambios en los patrones de consumo energético.

Se puede anticipar que en el futuro los requerimientos de energía crecerán. El énfasis reciente en estrategias de desarrollo se ha situado en la provisión de necesidades básicas, definidas de varias formas, aunque usualmente incluyen alimentación, vivienda y agua. La energía es raramente incluída en la lista, a pesar de que su presencia es implícita en las otras necesidades. Ha sido mínimo el esfuerzo por cuantificar el contenido implícito de energía.

Para cada región, la elección entre sistemas de oferta de energía dependerá del clima local, recursos, economía y otras variables. Determinar la adecuación de un tipo particular de oferta de energía es especialmente difícil para nuevos y no convencionales recursos renovables.

Parámetros culturales y de equidad nos interesan por dos razones relacionadas. Primero, los costos y beneficios no cuantificables o de difícil cuantificación, resultan importantes en la determinación del valor e impacto de proyectos tanto en países en desarrollo como en áreas desarrolladas. Y segundo, las nuevas tecnologías energéticas que no corresponden directamente con la demanda de energía e ingresos de los usuarios-objetivo, serán adoptadas con grandes dificultades, sin importar el énfasis de los programas asistenciales.

Los patrones de distribución del ingreso y de la propiedad existentes condicionan fuertemente el acceso de hogares de bajos ingresos a los recursos energéticos. Altos costos de capital inicial están más allá de su alcance, aún cuando sean económicos. Los aspectos de necesidades energéticas en países en desarrollo, raramente han sido tema de pruebas de campo o programas piloto. 
Dependiendo del marco de preferencias de las poblaciones locales - parcial pero no completamente perfiladas por los niveles de ingreso-, estas necesidades tendrán diferentes prioridades. Las variadas fuentes energéticas pueden corresponder más o menos a las demandas por un particular tipo de calefacción $\longrightarrow$ de refrigeracion -0 significados sociales o religiosos. Los marcos de preferencias culturales han jugado claramente su parte en la falta de aceptación de las cocinas solares, estufas eficientes, y plantas de biogás.

Cuando los ingresos son demasiado bajos, la electricidad, como bien de consumo, a menos que esté altamente subsidiada, podría permanecer limitada a un pequeño grupo de los que están relativamente mejor. Es posible que cualquier nueva tecnología energética que se introduzca a estructuras sociales muy desiguales, sea más aprovechada por hogares más ricos y favorecidos, quienes así, serán capaces de fortalecer su posición.

La gente de bajos ingresos, por definición no puede utilizar sistemas energéticos caros. Los enfoques que se pueden seguir para nivelar el acceso incluyen: 1) políticas crediticias que permitan a hogares pobres distribuir su gasto en un periodo mayor de tiempo; 2) arreglos técnicos o subsidios que permitan abaratar el precio de la energía.

Puede afirmarse que las consideraciones sobre preferencias y patrones de distribución del ingreso deberán jugar un rol importante en futuros programas asistenciales de energía. Las tecnologías energéticas más exitosas parecen ser aquéllas que requieren sólo de alteraciones marginales en prácticas cotidianas e institucionales.

\section{Sector eléctrico y empresas de servicio público}

Primeaux Jr. y Mann (1986) indican que la regulación de empresas de servicio público ha sido objeto de intensas críticas. La conveniencia de objetivos tradicionales de regulacion, como serían el control de ingresos -prevención de utilidades monopolicas-, control de precios - prevención de excesiva discriminación de precios-, y el control del servicio público, se ha visto impactada por variables exógenas. Entre ellas destacan altas tasas de inflación, crecimiento del número de usuarios, oferta decreciente de combustibles baratos, cambio tecnológico y creciente preocupación ambiental. La cuestión regulatoria se vuelve hoy mucho más difícil.

Entre las propuestas que se discuten en el contexto estadounidense se ha mencionado la ventaja de integrar comisiones reguladoras a partir de un proceso de elección respecto al de designación para el cumplimiento de sus funciones. Se han investigado los efectos de ambas opciones en el nivel y estructura tarifarias. 
En esta dirección, Mann (1974) ha examinado la significancia del poder político en la determinación de tarifas eléctricas. Por su parte, Primeaux y Nelson (1980) emplearon para ello dos enfoques amplios: el de beneficios y el de redistribución derivados de la regulación.

El primer enfoque plantea la existencia de grupos de interés que buscan capturar el proceso regulatorio persiguiendo fines particulares; el segundo, enfatiza que la regulación no permite evadir el cruzamiento de subsidios entre clases de usuarios.

Trebing (1981) utiliza categorías similares: la idea de captura, la del surgimiento de coaliciones y la de estabilidad-de-la-equidad. Según esta última, los reguladores actúan en protección del público, de los efectos directos de las fuerzas de mercado, situación en que las consideraciones de equidad predominan sobre las metas de eficiencia.

La teoría de captura puede atribuirse a Stigler (1971) al establecer que la regulación generalmente es capturada por la industria regulada y operada básicamente para su beneficio, aun cuando se reconoce el potencial de otros grupos políticamente efectivos.

A su vez, la teoría redistributiva puede adjudicarse a Posner (1974), según la cual, el comportamiento regulatorio es influenciado por varias coaliciones de grupos políticamente efectivos. Con ello la regulación puede percibirse como un sistema de financiamiento público que permite una subsidización cruzada.

Un aspecto de interés en la discusión es analizar si el modo de integrar el organismo regulador tiene efectos en la determinación de precios. Se podría especular que el arreglo regulatorio debe tener mayor impacto sobre la determinación tarifaria en etapas recientes - de regulación activa-, respecto a etapas anteriores - de regulación pasiva. Sin embargo, Samuels (1973) señala cómo los organismos reguladores podrian perseguir diferentes objetivos, los cuales generalmente son complejos y cambiantes.

Hagerman y Ratchford (1978), se centraron en variables económicas y políticas que afectan las tasas de retomo observadas. Sus resultados ofrecen una visión de los nexos entre arreglo regulatorio y sus resultados. Variables tales como riesgo, tamaño de planta, método base de valuación y tasas de interés prevalecientes influyen sobre las tasas de retomo. Los periodos breves para el nombramiento de comisionados parecen conducir hacia una mayor sensibilidad social. El método de selección del regulador resultó no ser estadísticamente significativo en este estudio.

Posteriormente, este resultado se fortalece cuando Harris y Navarro (1983), utilizando datos transversales, concluyen que la aparente relacion entre menores tarifas y estados con comisiones electas no puede atribuirse estadísticamente al método de selección. 
Los resultados globales de Primeaux Jr. y Mann (1986) han indicado que el procedimiento de selección del regulador no tiene un impacto significativo y consistente sobre los precios de la electricidad. Sin embargo, se espera que la magnitud de los movimientos o cambios en la importancia del procedimiento resulte en lo sucesivo más relevante.

Algunas propuestas para reformar la regulación en la industria eléctrica estadounidense, enfatizaron el potencial competitivo de las plantas generadoras aunque han sido menos optimistas acerca del rol de las fuerzas del mercado en la distribución eléctrica. Mientras que la tecnología de la generación eléctrica se examina en detalle, la magnitud de las economías de escala en transmisión y distribución son menos claramente comprendidas.

La dificultad en el análisis de los efectos de escala en industrias que entregan su producción a un grupo espacialmente disperso de consumidores, tales como la electricidad, la televisión por cable, agua potable o gas natural, consiste en que la expansión del producto puede darse de varias maneras: a) incremento en la demanda de consumidores fijos; b) demanda de nuevos consumidores dentro de la misma área de servicio de la empresa; c) una expansión del área de servicio de la empresa.

Roberts (1986), desarrolla tres medidas de las economías de densidad y tamaño que son útiles en el análisis de la estructura de costos. Sus resultados empíricos indican que la fuente importante de declinación en el costo promedio es el incremento de la cantidad de producto consumida por usuario, y no el incremento en la densidad de consumidores o en el área de servicio. En promedio, un incremento de $1 \%$ en el producto, manteniendo constantes el número de usuarios y el área de servicio, conduce a $0.82 \%$ en el costo total.

A su vez, no existen economías significativas resultantes de un aumento en la densidad de consumidores, debido a que el aumento en el producto es compensado por un desplazamiento hacia arriba de la funcion de costos medios, debido al aumento en el número de usuarios. Una de las implicaciones de la competencia entre firmas dentro de una determinada área de servicio, es la declinación de la densidad de usuarios, sugiriendo las conclusiones de investigación que no necesariamente habria pérdidas sustanciales de eficiencia como resultado. El resultado empírico final es que, en promedio, no existen ahorros sustanciales en los costos medios resultantes de un incremento en el tamaño geográfico del área de servicio de la firma.

Nelson y Primeaux Jr. (1988) han estudiado los efectos de la competencia en los costos de transmisión y distribución eléctrica. Parten de señalar que la inconformidad con las crecientes tarifas eléctricas, junto con el éxito de la desregulación en el transporte, comunicaciones y sector 
financiero, condujeron a un número de propuestas para la total o parcial desregulación de la industria eléctrica. Muchas de esas propuestas asignaron un papel importante a la competencia en la generación mientras mantuvieron la regulación o propiedad pública de la distribución eléctrica, ello debido al supuesto de que se trata de un monopolio natural.

El supuesto fue objeto de ataques frecuentes a partir de fines de los setenta. Primeaux $(1975,1977,1986)$, ha examinado los efectos de la competencia en la industria eléctrica municipal, encontrando que ésta reduce los costos por kwh en aproximadamente $11 \%$, resultado atribuido a la reducción en eficiencia-X. La competencia directa en transmisión y distribución de electricidad a un conjunto dado de consumidores, podría tener dos efectos: a) reducción en costos debido a la eliminación de ineficiencia- $\mathrm{X}, \mathrm{y}$ b) cambios en costos asociados con economías de escala.

Resultados de Nelson y Primeaux Jr. han cuestionado el supuesto de monopolio natural en la transmisión y distribución eléctrica. Las economías de escala respecto a los incrementos simultáneos en el producto y número de consumidores - manteniendo constante el producto por consumidor-, parecen agotarse en las empresas más grandes de la muestra. Este resultado tiene implicaciones sobre la estructura del mercado e indica que la competencia puede ser deseable en mercados grandes en donde las economias por densidad se han agotado.

\section{Determinación de tarifas por servicio eléctrico}

Los estudios que abordan el impacto social de la determinación de precios y tarifas de empresas de servício público, contemplan tanto efectos directos como indirectos sobre el consumidor final.

En el contexto estadounidense, Cray (1989), ha generado información sobre el proceso de transmision del ajuste de precios sobre la economía regional y la identificación de sectores afectados. Su análisis considera, a su vez, el límite superior de impacto de tales ajustes sobre el sector residencial. Entre sus hallazgos, se menciona al sector servicios como uno de los más impactados, aunque los efectos acumulativos sobre usuarios residenciales puedan ser sustanciales y causa de importante reducción de su poder adquisitivo.

El estudio menciona que en opinion de los integrantes de la Asociación Nacional de Consumidores de Empresas Públicas estadounidense, su gobierno federal ha estado históricamente más dispuesto que los gobiernos estatales, a brindar asesoramiento a consumidores sobre los costos asociados a inversiones no económicas realizadas por las empresas. $\mathrm{La}$ distancia política y geográfica entre grupos diseñadores de políticas y las 
áreas afectadas, tendría que considerarse. De ahí surge la posibilidad de que algunas regiones del país resulten —ceteris paribus — más vulnerables que otras a mayores incrementos tarifarios.

Al examinar el impacto del precio sobre el sector residencial, su interés se centra en la determinación del cambio total en precios que experimentan los usuarios en una región. Los incrementos derivados de las modificaciones en tarifas eléctricas, representan reducciones en el poder adquisitivo del usuario promedio. Con el tiempo, éstos buscarán modificar los patrones de consumo, así como las empresas, transformar sus procesos productivos.

En el caso en que la generación eléctrica se apoya en la disponibilidad regional de recursos naturales, como sería el caso de la hidro y geotermoelectricidad, la discusión incorpora matices particulares.

Hertel y Mount (1985), indican que los pasos hacia la descentralización de la toma de decisiones en materia de políticas públicas en Estados Unidos, algunas veces llamado nuevo federalismo, han conducido a un incremento en el número de iniciativas de desarrollo económico de base regional.

Uno de los instrumentos utilizados en la atracción regional de actividades económicas ha sido la determinación de precios en materia de recursos naturales controlados por el sector público. En su trabajo se analizan los efectos de la aplicación de subsidios sobre recursos naturales y el impacto de esquemas alternativos de costos similares. El recurso bajo consideración, es la generación bidroeléctrica por empresas públicas en Nueva York.

Entre las implicaciones de corto plazo analizadas, considera: 1) la opción de estimular el crecimiento económico mediante un modelo que establece un conjunto de subsidios al trabajador, que son iguales en costo a los subsidios eléctricos; 2) subsidios a la producción; 3) no subsidios. En un modelo competitivo, la eliminación de subsidios conduciría a un incremento del ingreso real, atribuíble a una utilización más eficiente de los recursos estatales. En la misma dirección, opera la transferencia de ingresos al Estado para cubrir "pérdidas" económicas de los sectores que enfrentan costos unitarios de producción divergentes.

La relación complementaria entre factor trabajo y electricidad se espera conduzca a una disminución del empleo en el Estado. Concluye la conveniencia de que la energía se venda al sector manufacturero a la misma tarifa de usuarios residenciales y comerciales. Esto tiene el beneficio adicional de promover el ahorro de energía. El reemplazo de los subsidios eléctricos, con equivalentes subsidios a la producción, es recomendable. El subsidio a la producción actúa directamente sobre los costos unitarios mientras que el subsidio eléctrico es afectado por un factor de sustitución. 
Los efectos del precio de la electricidad y del ofrecimiento de créditos en la adopción de sistemas tecnológicos, basados en la energía solar han sido estudiados por Durham, Colby y Longstreth (1988).

En 1977 el Acuerdo Nacional de Energía estableció créditos fiscales a usuarios residenciales para cubrir una parte sustancial del costo de instalaciones para el calentamiento de agua y calefacción de viviendas. Cuarenta estados ofrecieron incentivos financieros adicionales para estimular la instalación de sistemas solares. Sin embargo, hacia fines de los años ochenta, estos mecanismos expiraron sin posibilidad alguna de ser renovados.

Además de la controversia sobre la justificación de los incentivos, existe debate sobre su efectividad. Los resultados empíricos indican que el costo de fuentes de energía convencionales, nivel del crédito estatal, nivel de escolaridad del jefe de familia y el número de residentes de la vivienda, están todos significativamente relacionados con la adopción de equipos para calentamiento de agua. Los resultados son relevantes en la arena de las políticas públicas, debido a que las dos variables más significativas - crédito y precio-, son ambas altamente influenciadas por decisiones políticas.

La teoría económica presenta un modelo de comportamiento del consumidor basado en la maximización de utilidad. Un individuo o usuario adquiere la canasta de bienes y servicios que aportan la mayor utilidad dada su restricción presupuestal. La selección entre canastas se basa en costos y beneficios percibidos. La decisión de adquirir un bien durable, como un calentador solar, es compleja, implicando un sustancial costo inicial y un conjunto de beneficios y costos sobre la vida útil de la unidad. Los hogares de altos ingresos son, siendo todos los otros factores constantes, más propensos a adquirir bienes durables "ahorradores de energía" que los hogares de bajo ingreso.

La literatura especializada sobre determinantes sociales y demográficos de la adopción de equipos solares y otras medidas de conservación, muestra vínculos entre nivel de ingreso, educación, tamaño de la familia y adopción de prácticas de ahorro de energía.

En el contexto estadounidense, Sexton, Jong-Wen Wann y Kling (1989), han analizado los efectos de la disponibilidad de información en materia de ahorro energetico y bienestar en experiencias de tarifa-horaria (time-of-day TOD pricing). En su estudio, señalan que el tema fue ampliamente discutido y analizado en materia de iniciativas para el ahorro de energía durante los ochenta. Sus resultados muestran que los instrumentos de monitoreo tienen impacto sobre la distribución del consumo eléctrico entre periodo-pico (peak period) y el resto del periodo (off-peak period). 
Miedema, Lee y White y Aigner, concluyeron que las tarifas-horarias (TOD) logran reducir el consumo en el periodo-pico relativo a control, aunque usualmente tengan un efecto insignificante sobre el resto. Aigner concluyó que la tarifa-horaria se justifica en costo sólo en casos especiales, por ejemplo, usuarios de muy elevado consumo de kilowatt-hora que utilizan aire acondicionado.

El estudio de Sexton, Jong-Wen Wann y Kling (1989), sin embargo, demuestra que aunque el beneficio en el manejo de la carga de energía eléctrica puede ser importante para la empresa, la utilidad para el usuario no justifica el costo de adquisición de los monitores, y además el impacto sobre el ahorro total generalmente es pequeño $o$ inexistente.

\section{Diseños tarifarios ante objetivos sociales}

Michael Hennesy y Dennis M. Keane (1989), evaluaron el diseño tarifario en California, Estados Unidos en relación con el objetivo de lograr beneficios para los hogares de menores ingresos. Su estudio propone diseños que permiten generar montos equivalentes de recuperación. Utilizando datos representativos a partir de un marco muestral e informacion demográfica, se señalan alternativas y se comparan con la tarifa vigente.

En 1975, las tarifas residenciales en Califomia, Estados Unidos se justificaron sobre la base de dos supuestos: 1) la luz y el calor son "derechos humanos básicos que deben ser disponibles a toda la gente al menor costo para cantidades mínimas básicas"; 2) la decreciente estructura de tarifas residenciales vigente, penaliza a los consumidores de pequeña escala y alienta el desperdicio en épocas de escasez de energía.

Sobre estas consideraciones, la legislación reemplazó tarifas decrecientes por un diseño con tasas invertidas. En ese diseño, el primer grupo o grupo mínimo (lifeline-block) definía la provisión para "necesidades esenciales" de calefacción ambiental, calefacción de agua, luz, cocina y refrigeración de alimentos. Se estableció que el monto debería variar según las condiciones climáticas en el estado y según la temporada, aclarando que no debería superar las tasas vigentes ni cambiar hasta que el promedio del sistema de tarifas se incrementara más de $25 \%$. El problema era determinar el monto de la "necesidad esencial".

Para 1978 la enmienda AB2273 estableció el aire acondicionado como "esencial" para todos los usuarios que residen en las regiones cálidas del estado.

El paso de criterios de tarifa mínima (lifeline-block) a tarifa básica (baseline-block) en 1982, reiteró la estructura invertida de la tarifa con el fin de promover el ahorro de energía, pero descartó criterios de uso-final 
para determinar el monto básico. En su lugar, la legislación definió al monto básico como "de 50 a 60 por ciento del consumo residencial promedio" para la mayoría de los usuarios residenciales, y "de 60 a 70 por ciento del consumo promedio residencial" durante el invierno, para los usuarios con residencia totalmente electrificada.

La legislatura estableció una regla para el precio de la electricidad vendida en el bloque básico. El monto sería entre "un 15 a 25 por ciento abajo del promedio del sistema de tarifas". La legislatura californiana determino así tanto la forma como el cálculo del precio de la tarifa básica.

Dado que la utilidad determina los requerimientos de ingreso para cada clase de usuarios de manera separada, el efecto práctico de estas restricciones es limitar el monto que puede captarse por ventas a usuarios ubicados en el primer nivel. Como los requerimientos de ingreso aumentan en el tiempo, esta restricción forza a las utilidades a captar porciones crecientes del ingreso, aumentando el precio para el segundo nivel de consumo.

En 1987 se consideraron varias enmiendas, culminando con la SB987. En ésta, aunque se mantiene el concepto de tarifa invertida (creciente), le da flexibilidad a las empresas en California para alterar la relación de precios entre el primero y el segundo nivel de consumo con el argumento de que "un programa de asistencia a usuarios de bajo ingreso de electricidad y gas sería disponible a usuarios para controlar grandes incrementos de facturaciones".

El aumento en la actividad legislativa hacia fines de los años ochenta mostró de nuevo que la tarifa básica significa una cuestión política importante en el estado de Califomia.

La racionalidad de la estructura de tarifas varía. Aunque no hay un acuerdo universal, algunas combinaciones de los siguientes tres propósitos se mencionan generalmente : 1) Proveer un monto básico de electricidad a bajo precio; 2) Promover ahorro de energía (conservación); 3) Asistir a usuarios de bajo ingreso para los cuales las altas tarifas eléctricas son un problema particularmente difícil.

Las tarifas básicas hacen disponibles cantidades mínimas de electricidad a un precio menor que el promedio. Esto no significa que las facturaciones a los usuarios residenciales necesariamente decrecen. Debido a que el ingreso total de usuarios residenciales debe recaudarse y los usuarios de primer nivel pagan por abajo del promedio, se requieren más altos precios para el consumo que rebase el nivel básico. Hogares de bajo consumo necesariamente pagan baja facturación y a la inversa. La legislación creó un esquema bajo el cual los grandes usuarios subsidian a los pequeños usuarios. 
Las tarifas básicas han hecho emerger cuestiones prácticas relacionadas con el manejo de poblaciones-objetivo, excedentes de consumo y efectos de conservación o ahorro. En este sentido, resulta útil considerar cuatro categorías de hogares según uso de energía y estatus de pobreza (Hennesy \& Keane, 1989):

Hogares de bajo uso de energía-bajo ingreso. Son indiferentes a la elección entre propuesta de tarifa dirigida y tarifa universal debido a que para el primer nivel la tarifa es identica en ambas propuestas.

Hogares de alto uso de energía-bajo ingreso. Son inequívocamente mejorados por la tarifa dirigida, debido a que sus costos de uso en el primer nivel son los mismos pero en el segundo nivel se les cobra con una tarifa menor a la tarifa universal.

Hogares de bajo uso de energía-no bajo ingreso. Debido a que deben pagar la tarifa constante en lugar de la básica subsidiada, estos hogares pierden bajo el diseño de tarifa dirigida. El monto de su pérdida es generalmente pequeña debido a que el subsidio perdido se aplica a cantidades limitadas de energía.

Hogares de alto uso de energía-no bajo ingreso. Los efectos dependen del nivel de uso de la energía. Ellos pagan un precio alto por las ventas de primer nivel bajo la tarifa dirigida pero un precio bajo por las de segundo nivel. Un punto de inflexión en las ventas puede calcularse para cualquier hogar (baseline). Los hogares que consuman en exceso del punto de inflexión ahorrarán, bajo la tarifa dirigida. (El monto de ahorro se incrementa con el uso, otorgando un incentivo deseable para ventas mayores).

Ambos tipos de propuestas pueden encontrar resistencia tanto por la regulación como por los consumidores, planteándose un conjunto de dilemas. Un tipo de propuesta otorga beneficios a todos los hogares de bajo-ingreso pero implica incrementos en factura relativamente altos en hogares no-pobres. La otra propuesta puede tener problemas por imponer un cargo que no es aplicable a todos los hogares de bajo ingreso, lo cual no necesariamente beneficia a dichos hogares.

El primer dilema plantea la interrogante de quién paga por la aplicación de la tarifa básica. Bajo el diseño actual, sólo las ventas para consumo residencial serán utilizadas para financiar el descuento correspondiente. Se asume que los usuarios residenciales "deben pagar" tal descuento pero no es evidente que los otros tres tipos de consumidores: industriales, comerciantes y agricultores, no deban asistir para alcanzar esta política social.

La posibilidad de distribuir la responsabilidad sobre otros usuarios tiene varias ventajas. Primero, es más equitativa, pues la pobreza es un problema social; segundo, la ventaja política de afectar a todos los tipos de usuarios. 
El segundo dilema cuestiona el objetivo de dirigir (población-objetivo) las tarifas residenciales. Hay controversia, sobre todo cuando el criterio de dirección no se refiere al consumo del usuario. Se argumenta que la tarifa debe ser socialmente neutral o que no se debe atender al impacto social de su diseño. Sin embargo, esto resulta políticamente ingenuo porque los principios de regulación enfatizan la relación inversa entre determinación de tarifas para el interés público y el financiamiento formal de un estatus de monopolio.

Un tercer dilema se refiere a la forma en que deben distribuirse los beneficios de la tarifa básica. La primer propuesta supone que los descuentos cuando menos no cambien para los hogares pobres y algunos de los hogares pobres que son grandes usuarios, tengan reducciones en sus facturas. La segunda propuesta en contraste, fue diseñada para asignar una reducción mensual de cinco dólares a todos los hogares pobres mediante una tasa general mayor. Ambos diseños implican un descuento variable a los hogares pobres. Subsiste el problema de determinar el nivel de descuento necesario para "ayudar al pobre".

En conclusion, los dilemas particulares son instancias de problemas de política que emergen cuando fines sociales son combinados con una determinación monopolística de precios.

Las tarifas básicas son un ejemplo particular dada la naturaleza "sumacero" del problema: bajo todos los diseños de tarifa residencial, el ingreso total requerido significa una constante regulatoria obligada. La única flexibilidad está en reducir la factura a algunos e incrementarla a otros sobre bases que no estén relacionadas con costos del servicio. Mientras los requerimientos de la recaudación para la clase residencial sean fijos, la reforma tipo tarifa básica en California, permanecerá como una cruzada simbolica sobre todas las dimensiones económicas, políticas y de equidad.

\section{La tarifa eléctrica en México}

En el diseño tarifario poseen tanta relevancia aspectos relacionados directamente con la determinación de precios como las repercusiones que en el precio de la energía tiene un adecuado control de la demanda. Las condiciones particulares de que participa el suministro eléctrico conducen a métodos distintos para la fijación de precios, en este caso, por medio de esquemas tarifarios. (Figueroa, 1988b).

Al coincidir la mayor demanda de servicio con cierto horario se da lugar a los llamados "picos" (peaks) en la curva de la demanda del sistema eléctrico; es decir, existe un periodo dentro del cual el equipo funciona a plena carga y otro en el que sólo funciona a una fracción de su capacidad. 
En el suministro eléctrico no es posible el almacenamiento del producto. Por el contrario, la energía se produce en las mismas plantas y es liberada en el lugar requerido y en el momento deseado por el usuario.

Una parte mayoritaria del costo se determina por el capital necesario como inversión para atender cargas conectadas a usuarios: el costo depende de los kwh o energía suministrada. Este costo puede considerarse fijo, ya que no depende de la generación.

Algunas tarifas contienen precios menores conforme aumenta el factor de carga del servicio, pues esto favorece el uso uniforme del equipo de utilización del cliente. Cada grupo de usuarios tiene horas-pico dentro del sistema eléctrico, explicando la existencia de diversas tarifas con diferentes cuotas.

Terricamente, las tarifas contienen tres cargos fundamentales; costo comercial, costo financiero (demanda) y costo de energía (kwh).

La industria eléctrica se sujeta a la regulación estatal, a través de la Secretaría de Hacienda y Crédito Público. El sector no puede cobrar cualquier precio derivado de ajustes que considere procedentes.

La capacidad del sistema debe ser lo suficientemente grande para afrontar la demanda máxima de todos los usuarios. Una parte importante de los gastos de operación de un sistema eléctrico, está más relacionado con su capacidad instalada que con la cantidad de kwh requeridos por los usuarios.

El cliente crea la demanda y el sector cobra un cargo adecuado por equipo, instalaciones, etcétera, destinados a afrontar esa demanda. El factor de carga es el cociente que resulta de dividir demanda media entre demanda máxima.

Durante más de dos décadas funcionó el sistema tarifario denominado "demanda base de facturación", consistente en facturar un servicio conforme a la demanda que resulte mayor entre la contratada y la medida. Una condición que debe reunir un servicio eléctrico para tener un factor de carga cercano a la unidad, consiste en tener una curva de duración de carga tan parecida a un rectángulo como sea posible.

La administración de la demanda consiste en eliminar picos de la curva de carga de cualquier servicio, de forma que el mismo volumen de consumo se haga dentro de las horas de los valles de la misma curva.

Entre las consideraciones legales pertinentes, Figueroa (1988b), ha argumentado que para lograr el uso racional de la energía, debiera incluirse en la reglamentación respectiva de la Ley del servicio público de energía eléctrica, la creación de una "Ley sobre uso racional de la energfa", incluyendo en ella previsiones necesarias acordes con dicha ley. 


\section{El subsidio al consumo eléctrico básico}

En México, el nivel de precios de los bienes y servicios urbanos (agua, transporte, alumbrado público, etcétera) tradicionalmente ha sido más bajo en el Distrito Federal que en otras grandes ciudades del país. La ciudad de México goza de un sistema de precios relativos de los bienes y servicios urbanos, muy favorable frente al resto de las ciudades del pais.

La magnitud de los subsidios es tan elevada que éstos constituyen un componente fundamental del precio de los bienes y servicios urbanos. (Perlo, 1990).

Un punto de vista extendido es que el subsidio es responsable de graves problemas financieros. Uno de esos problemas son la ineficiencia con que se operan, administran y cobran los servicios urbanos. Los problemas de cobro de servicios, impuestos y derechos son generalizados.

Una falla del enfoque mencionado ha sido concebir al subsidio únicamente desde un ángulo contable, es decir, como cifra global que debe reducirse a toda costa, sin considerar su desglose particular y sobre todo, sin analizar el papel económico, social, político y urbanístico que desempeña.

Debe reconocerse, en cambio, que algunos subsidios están claramente dirigidos a beneficiar la economía familiar, evitando que los costos urbanos recaigan sobre sectores de menores ingresos y cumpliendo una función productiva al facilitar la movilidad de la población.

Otro punto de vista señala que los subsidios deben mantenerse porque estos cumplen una función eminentemente social y política, ya que son un mecanismo redistributivo en favor de aquellos sectores de menores ingresos dentro de la sociedad.

Sin embargo, aunque algunos de los subsidios alcancen a beneficiar a los sectores de población de ingresos medios y bajos, otros son aprovechados predominantemente por grandes empresas industriales, comerciales y de servicios, así como por sectores sociales de mayores ingresos. De esta manera, la equidad entre los distintos usuarios se ve desequilibrada.

La respuesta se encuentra, desde la perspectiva señalada por Perló (1990), en un punto intermedio entre estas dos posiciones. Es necesario reducir subsidios en forma paulatina y selectiva, analizando caso por caso, eliminando aquéllos que no cumplen una función social. Aquellos subsidios que sí se mantengan deben por una parte, llegar en forma transparente a los grupos sociales que verdaderamente lo necesitan y por otra, servir para impulsar políticas que permitan bacer una mejor planeación urbana. 


\section{MODELO DE LA FUNCIÓN CONSUMO ELÉCTRICO RESIDENCIAL}

\section{Economía energética}

Se define a la economía energética como rama de estudio multidisciplinario encargada de analizar condiciones de produccción, distribución y utilización de la energía ya sea como factor productivo, como bien de consumo final o como fuente de financiamiento. El objetivo consiste en buscar la optimización de su uso y el estudio de los elementos que integran las etapas de actividad, es decir, uso, producción y distribución. (Unteaga, 1988).

Diversos enfoques comprenden el estudio económico de la energía como: a) factor de producción, b) bien de consumo final, c) fuente de financiamiento, d) elemento estratégico del sistema económico internacional, e) actividad fundamental para el crecimiento económico.

Variadas metodologías utilizadas para la realización de estudios energéticos consideran necesario examinar las características del consumo, de las formas y fuentes de energía, así como del nivel en el balance nacional de energía. Asimismo, explorar posibilidades de eficiencia energética e implementación de programas para el ahorro y conservación de energía.

\section{Demanda de energía y bienestar}

En la década de los setenta, surge un sistema de planeación energética que contempla tanto demanda como generación de energía, de donde surgen conceptos como el de la administración de carga, modificación de patrones y magnitud de carga del servicio. (Rivas, 1990:83).

Para lograr modificaciones en el perfil de la curva de carga, se precisa profundizar el estudio regional de la demanda de energía. La metodología debe considerarla como sistema dinámico, antes que cantidad fija y predeterminada, considerando además el contexto que envuelve a dicho sistema.

En una de las propuestas metodológicas se contempla:

a) Caracterización del sistema eléctrico regional, al identificar elementos del entorno como población, geografía, clima, etcétera. Dimensionamiento de los niveles jerárquicos del sistema eléctrico: 1) generación, suministro y administración de energía; 2) sistema de consumo unitario dividido en zonas; y 3) subdivisión del consumo unitario en residencial, industrial, comercial u otro tipo. Con ello se determina el subsistema demanda. 
b) Desarrollo de modelos económicos que permitan la construcción de escenarios deseables mediante técnicas estadísticas. En el caso de la demanda intervienen variables como tipología de consumidores y usos finales.

c) Análisis de resultados del modelo y con base en ellos, implementación de políticas de decisión para incidir consumos y lograr un patrón de comportamiento que corresponda al escenario deseado.

Es deseable que en el diseño, implementación y evaluación de los programas sean considerados suficientemente, además de los elementos técnico-económicos, los aspectos sociales y culturales de la población en cuestión.

Debido a que los recursos energéticos derivados de los hidrocarburos son finitos, se hace necesario modificar hábitos y costumbres para implementar el uso de recursos renovables (Velasco, Ambriz y Romero, 1988). Se precisa evitar el desperdicio, para lo cual se requiere promover una cuidadosa educación en todos los niveles.

Los valores de consumo de energía per cápita son considerados actualmente, indicadores directos del grado de desarrollo de una sociedad o nación. Debe reconocerse que cualquier fuente alterna de energía, por sí sola, no será suficiente para satisfacer todas las necesidades de una comunidad.

El avance tecnológico y el bienestar material se determinan por factores de desarrollo y éstos pueden considerarse como primarios y secundarios. Los primeros se dividen en recursos humanos, energéticos y materias primas y los secundarios dependen de factores humanos.

En países desarrollados, una alta proporción de la energía consumida corresponde a la industria y al sector residencial. En México, los sectores industrial y de transporte son los principales consumidores. El sector industrial y las actividades de desarrollo tecnológico deberán buscar mecanismos que permitan disminuir la degradación de la energía, debido principalmente a las múltiples conversiones.

En el uso doméstico de recursos energéticos, este sector participa en una proporción relativamente baja en la estructura energética de consumo nacional. Sin embargo, de las actividades y normas de conducta originadas en los hogares dependerán en gran medida los resultados que en materia de ahorro de energía se obtengan en otros sectores.

Dentro del sector doméstico debe promoverse el uso racional de energía mediante programas estructurados que incluya campañas de concientización, a la vez que se tienda al cambio en usos y costumbres de aparatos domésticos, con objeto de mejorar su empleo reduciendo con ello el consumo. 


\section{Uso de energía en el sector residencial}

Un estudio elaborado por el Departamento de Energía de la Universidad Autónoma Metropolitana (Campero, Ortiz y Vargas, 1988), establece algunos lineamientos para el análisis del consumo energético en el sector residencial. Se analizan el efecto que tiene sobre el consumo, variables como son: vivienda, crecimiento de población, PIB, energía útil y prođucción de aparatos domésticos. México afronta problemas de vivienda que se complican debido a las tasas de crecimiento poblacional y a la falta de recursos económicos. El ritmo de construcción de la vivienda en el futuro, dependerá no sólo de la tasa de crecimiento demográfico y de los recursos gubernamentales, sino también de la recuperación del ingreso familiar.

La energía en el sector residencial se usa principalmente para cocinar, calentar agua, alumbrar y hacer funcionar aparatos domésticos. En lo que se refiere a preparación de alimentos, dado que la energía se mide en términos de energía entregada, el total para cocinar varía de acuerdo al tipo de combustible. Esto se debe a que la eficiencia difiere al utilizar combustibles diferentes. En México se utilizan gas natural, petróleo diáfano y electricidad. El gas licuado es más popular debido a su disponibilidad y menor precio. Aunque generalmente se use en estufas, éste no se limita al sector residencial.

El calentamiento de agua se puede llevar a cabo ya sea mediante calentadores que puedan quemar madera, papel, cartón o viruta de madera embebida en petróleo diáfano y que caliente el tanque de agua, o con calentadores de gas, con o sin depósito de agua.

En alumbrado, el sector residencial muestra que las lámparas incandescentes son más populares que las fluorescentes. En áreas no electrificadas se utilizan lámparas de petróleo diáfano o velas.

Respecto a aparatos domésticos, el refrigerador es el más vendido entre 1975 y 1985 (Campero, Ortiz y Vargas, 1988). Los consumidores potenciales de energía para aparatos domésticos son muchos, pero su tasa de crecimiento depende del comportamiento del ingreso familiar y de que la vivienda tenga la capacidad necesaria para satisfacer la demanda cuando ésta aparezca.

A partir de 1973, durante los cinco meses más calurosos del año, los usuarios residenciales de zonas muy cálidas del país cuentan con una tarifa especial más baja. La tarifa reducida ha tenido efectos en el consumo de energía en esas zonas, y no parece favorecer la conservación de la misma. De acuerdo al Programa Nacional de Energéticos 1984-1988, se delega a autoridades estatales y regionales la responsabilidad de hacer campañas para el uso racional de electricidad. 
Podría considerarse que el aumento en el consumo de energía en el sector residencial, a escala nacional, se debe al crecimiento de viviendas electrificadas o bien por la instalación de estufas o calentadores de gas en hogares donde antes se cocinaba con petróleo o leña, o no se contaba con instalación de agua corriente. La proporción que guarda el consumo de energía del sector residencial contra el resto de los sectores, irá creciendo en el futuro y los ahorros en este sector serán significativos para el país, pero sobre todo para la economía familiar.

\section{Especificación del modelo}

\section{Elasticidad-ingreso en la función consumo residencial}

La evidencia disponible sugiere considerar este parámetro como una variable estacional. A partir de estimaciones surgidas de la Encuesta EAAVCE (1990) se pasa a examinar la naturaleza de la asociación entre condiciones socioeconómicas, tamaño de la vivienda, estrategias de acondicionamiento térmico y consumos mensuales de energía eléctrica.

De este modo, se verifican cambios significativos entre los valores de la elasticidad-ingreso (ey) correspondiente al periodo de verano vis a vis los del resto del año. Si bien es cierto que todos ellos se ubican plenamente en un rango inelástico $\left(e_{y}\right)$, el nivel de inelasticidad pasa de valores promedio menores a 0.10 fuera del verano hasta de casi 0.17 durante esta temporada. Esto significa que cambios de cien por ciento en el ingreso familiar se espera modifiquen menos del diez por ciento el consumo de energía fuera del verano; en tanto que, para un mismo incremento del ingreso, el consumo eléctrico aumenta en promedio diecisiete puntos porcentuales durante el verano.

\section{Las variables independientes}

Se han utilizado como variables independientes aquellas que se introducen como elementos explicativos de la función consumo eléctrico. En este sentido, se incluyen:

a) el tipo de aparato utilizado en el acondicionamiento térmico de la vivienda durante la temporada de verano (APA), el cual fue medido en escala ordinal ascendente conforme a cuatro categorías;

b) el número de cuartos de la vivienda, como aproximación a las dimensiones de ésta (NUC), dado que en la aplicación de una encuesta extensiva hubiera resultado poco práctico efectuar constatación de los metros cuadrados de la vivienda; 
c) el ingreso familiar mensual medido en nuevos pesos (N\$) o miles de pesos viejos (IFA).

Resultados: análisis de caso para el consumo eléctrico residencial en Mexicali, Baja Callfornia, 1990

Los resultados se obtuvieron después de aplicar el método de mínimos cuadrados ordinarios, conforme a las especificaciones anteriores, de acuerdo con una serie de ecuaciones independientes correspondientes a cada mes del periodo de verano. Fue utilizado el método de "inclusión condicionada" (forward) del comando para regresión múltiple que presenta el paquete estadístico para ciencias sociales (SPSS V4.0).

El siguiente cuadro resume los principales hallazgos de este proceso:

CUADRO 7. Resultados estadísticos del modelo de regresión múltiple a la función consumo eléctrico residencial.

\begin{tabular}{|c|c|c|c|c|c|c|c|c|}
\hline $\begin{array}{l}\text { Consumo } \\
\text { Bléctrico }\end{array}$ & $\begin{array}{l}\text { Constante } \\
\text { (B) }\end{array}$ & $\begin{array}{l}\text { Tipo do } \\
\text { aparato } \\
\text { (NPA) }\end{array}$ & $\begin{array}{l}\text { Número de } \\
\text { cuartos } \\
\text { (Nuc) }\end{array}$ & $\begin{array}{c}\text { Ingreso } \\
\text { familiar } \\
\text { mensual (N\$) } \\
\text { (IFN) }\end{array}$ & R2 & $\mathrm{R} 2 \mathrm{a}$ & $\mathbf{F}$ & 8 \\
\hline \multicolumn{9}{|l|}{ Mayo } \\
\hline $\cos$ & $\begin{array}{l}85.56 \\
(1.72)\end{array}$ & $\begin{array}{l}49.57 \\
(3.28)\end{array}$ & $\begin{array}{l}18.61 \\
(3.13)\end{array}$ & $\begin{array}{l}.0229 \\
(3.25)\end{array}$ & .0520 & .0488 & 16.24 & .0000 \\
\hline \multicolumn{9}{|l|}{ Junio } \\
\hline $\mathrm{CO6}$ & $\begin{array}{l}-68.72 \\
(-1.22)\end{array}$ & $\begin{array}{l}112.07 \\
(6,58)\end{array}$ & $\begin{array}{l}23,02 \\
(3,43)\end{array}$ & $\begin{array}{l}.0344 \\
(4.32)\end{array}$ & .1115 & .1085 & 37.16 & .0000 \\
\hline \multicolumn{9}{|l|}{ Julio } \\
\hline $\mathrm{CO}$ & $\begin{array}{c}-437.33 \\
(-4.86)\end{array}$ & $\begin{array}{c}253.50 \\
(9.27)\end{array}$ & $\begin{array}{l}47.82 \\
(4.43)\end{array}$ & $\begin{array}{l}.0410 \\
(3.20)\end{array}$ & .1574 & .1545 & 55.30 & .0000 \\
\hline \multicolumn{9}{|l|}{ Agosto } \\
\hline Cos & $\begin{array}{r}-553.69 \\
(-6.72)\end{array}$ & $\begin{array}{l}317.99 \\
(12.70)\end{array}$ & $\begin{array}{l}57.54 \\
(9.86)\end{array}$ & $\begin{array}{l}.0165 \\
(1.40)\end{array}$ & .2264 & .2238 & 86.64 & .0000 \\
\hline \multicolumn{9}{|c|}{ Septiembre } \\
\hline $\mathrm{CO9}$ & $\begin{array}{c}-762.45 \\
(-6.88)\end{array}$ & $\begin{array}{l}337.08 \\
(10.07)\end{array}$ & $\begin{array}{l}65.93 \\
(4.96)\end{array}$ & $\begin{array}{l}.0620 \\
(3.93)\end{array}$ & .1875 & .1848 & 68.33 & .0000 \\
\hline \multicolumn{9}{|l|}{ Octubre } \\
\hline $\mathrm{C} 10$ & $\begin{array}{c}-375.81 \\
(-4.66)\end{array}$ & $\begin{array}{l}200.43 \\
(8.18)\end{array}$ & $\begin{array}{l}43.14 \\
(4.46)\end{array}$ & $\begin{array}{l}.0505 \\
(4.40)\end{array}$ & .1519 &, 1491 & 53.05 & .0000 \\
\hline
\end{tabular}

Fuente: Base de datos de la encuesta EAAVCE, 1990. UABC/IS, CFE, XIII Ayuntamiento de Mexicali (1990).

Nota: datos entre paréntesis indican estadístico t de Student. 
AGUSTIN SÁNDEZ PÉREZ

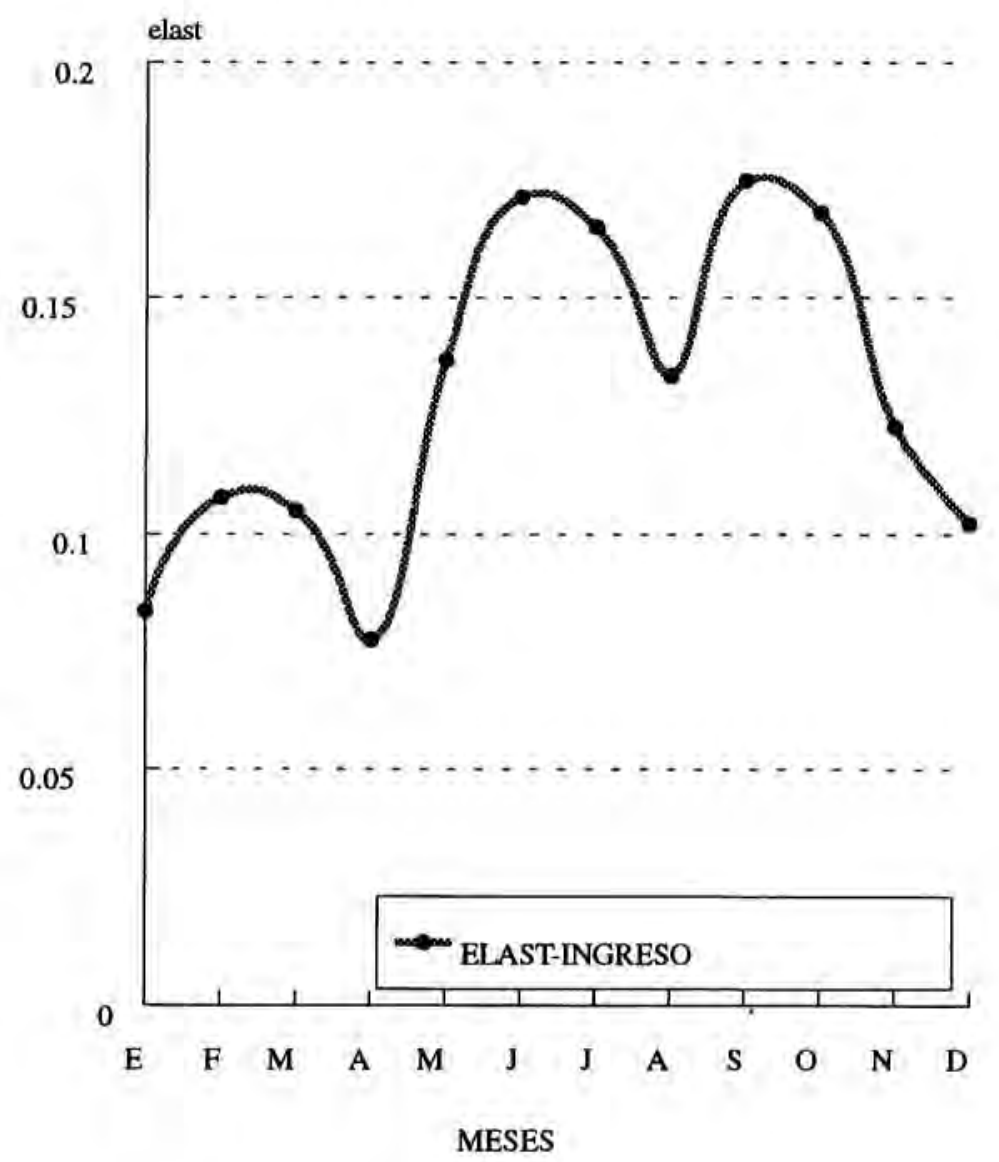

Figura 7. Modelo consumo eléctrico residencial. Elasticidad ingreso. Fuente: Encuesta EAAVCE.UABC/IS, CFE, XIII Ayuntamiento de Mexicali (1990). 


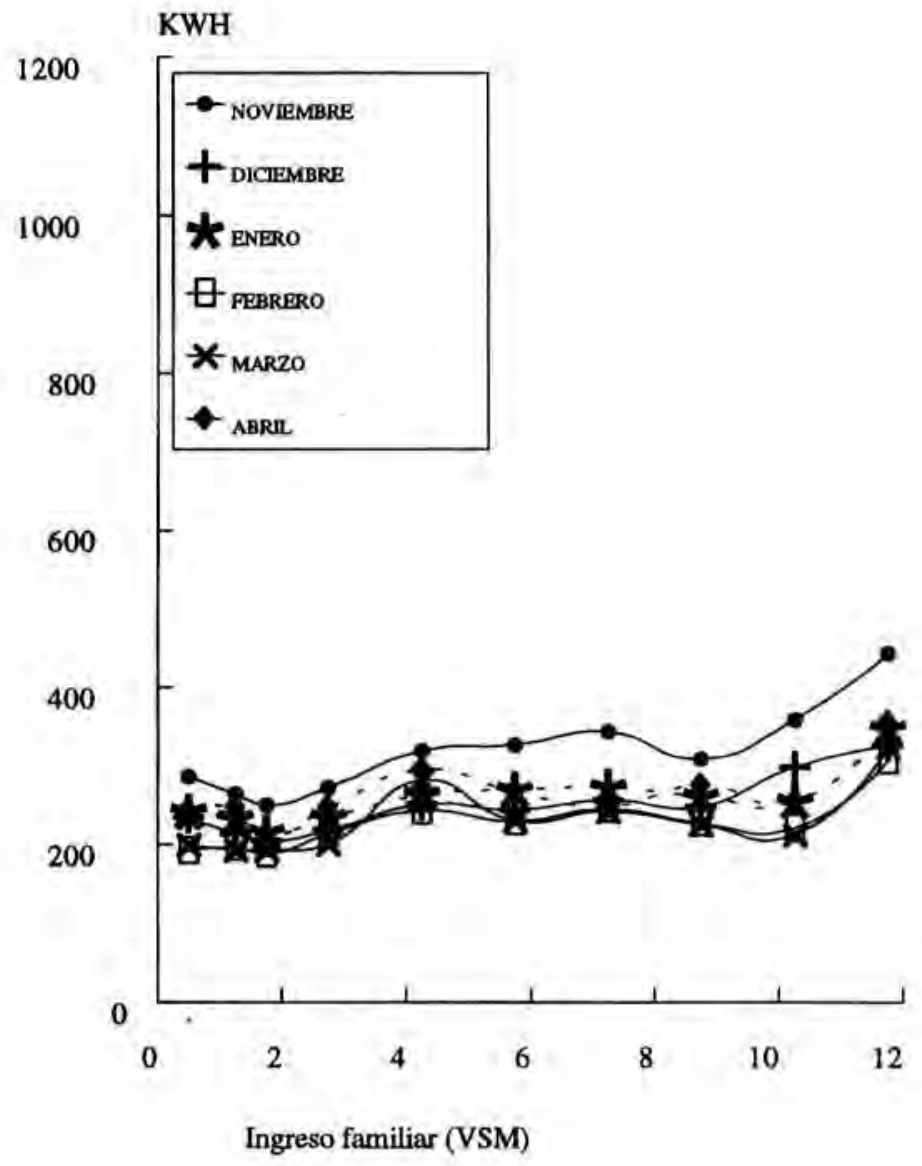

Figura 8. Modelo consumo eléctrico residencial. Noviembre-abril 1989.

Fuente: Encuesta EAAVCE, UABCMS, CFE, Xm Ayuntamiento de Mexicali (1990). 


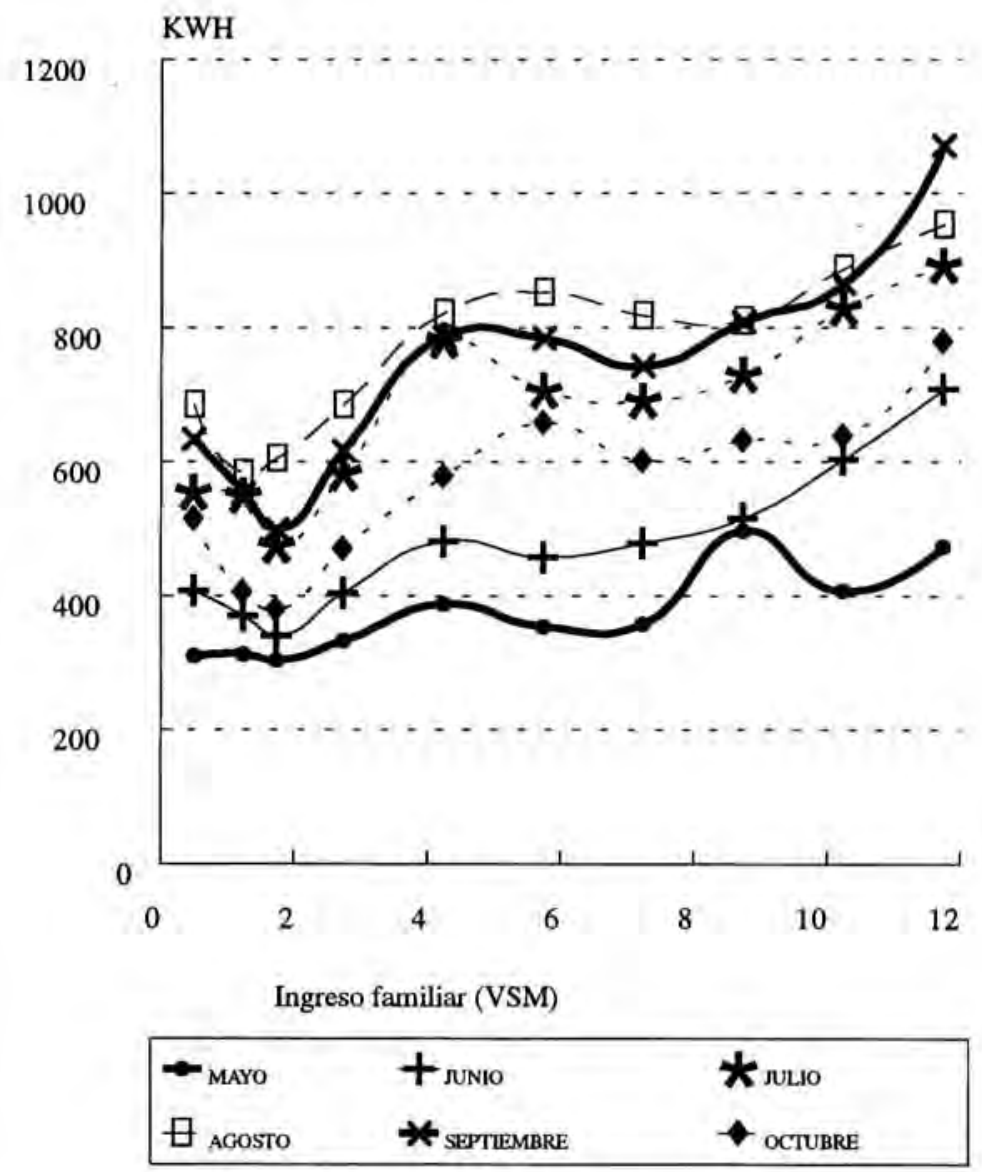

Figura 9. Modelo consumo eléctrico residencial. Mayo-octubre 1989.

Fuente: Encuesta EAAVCE, UABCתIS, CFE, XII Ayuntamiento de Mexicali (1990). 
Los resultados muestran cómo la inclusión de factores tradicionalmente concebidos como determinantes del consumo - al menos los más utilizados en la simulación-, no necesariamente garantizan obtener altos grados en la explicación del fenómeno. Tales variables podrían representar un conjunto inicial cuya naturaleza técnico-económica los hace significativos (confróntese estadístico de prueba $\mathrm{F}$ en las ecuaciones anteriores), aunque resultan insuficientes (véase los valores de la $R 2$ y $R 2$ ajustada correspondientes), en el intento de una explicación satisfactoria para la variable dependiente.

Como puede observarse, las variables convencionales estarían explicando menos de una cuarta parte de la varianza total del fenómeno. Ello significa que otro conjunto de factores - muy probablemente las relacionadas con prácticas sociales y estilos de vida-, estaría influyendo en una proporción muy considerable de los montos de consumo.

Entre los matices que habría que considerar o pudiesen ser relevantes hacia una discusión posterior, estaría la inclusión explícita de variables vinculadas al programa regular de actividades de los hogares (esto es, excluyendo las de periodos atípicos como vacaciones o cambios de residencia).

Este conjunto de variables podría representar un importante potencial explicativo del uso efectivo que se hace de los aparatos eléctricos, dadas las condiciones particulares que ofrecen las envolventes arquitectónicas particulares. La diversidad de las condiciones específicas en los "estilos de vida" familiares, seguramente explica la elevada varianza del consumo eléctrico apreciable en đistintos niveles de ingreso familiar.

Ello indica, contra toda preconcepción establecida, que una gran proporción del comportamiento del consumo eléctrico, depende críticamente de un conjunto de variables sociales referidas a las características particulares de las personas que integran un hogar y de sus actividades regulares. Incluso bajo las condiciones de inelasticidad de la demanda, no serán razones puramente técnicas ni económicas las únicas ni quizá las principales que explican el comportamiento del consumo residencial de energía eléctrica.

\section{CONCLUSIONES}

En la actualidad se presentan retos de magnitud considerable para el sector eléctrico, en especial los relacionados con el tipo de mecanismos que permitan financiar su crecimiento. El noroeste de México y en particular el estado, manifiestan características que hacen evidente la necesidad de un replanteamiento sustantivo a su estilo de desarrollo, orientando éste hacia un mayor esfuerzo en el uso racional de la energía eléctrica. 
Las características que presenta el consumo eléctrico en el noroeste de México, convierten a éste en un aspecto relevante en la planeación de su desarrollo, tanto si se considera el monto de recursos comprometidos como sus implicaciones sociales y ambientales. Dentro de ese contexto, la particularidad de la demanda de energía eléctrica de los habitantes del valle de Mexicali, resulta por demás específica. Constituye el punto más extremo en la distribución de una variable que destaca en el panorama de las zonas áridas septentrionales.

La relación entre ahorro de energía y gestión ambiental es altamente interactiva. La literatura documenta la inelasticidad de la demanda de energía, aunque igualmente señala la posibilidad de obtener menores valores después de cierto umbral de ingreso.

La regulación de empresas de servicio público ha sido objeto de intensa crítica a partir de mediados de los años ochenta. Se ha argumentado en favor de comisiones reguladoras cuya integración surja de una base participativa.

Aparentemente, la fuente importante de declinación de los costos medios, es el incremento en la cantidad consumida por usuario y no el incremento en la cantidad de consumidores o del área de servicio.

En materia de tarifas por servicio eléctrico, tendría que considerarse seriamente la distancia política y geografica entre los diseñadores de política y las áreas afectadas, pues surge la posibilidad de que algunas regiones resulten más vulnerables que otras a modificaciones tarifarias.

La racionalidad de una estructura tarifaria básica implica el propósito de proveer de montos básicos de electricidad a bajo precio, a la vez que se promueve el ahorro de energía. Es un hecho que los hogares de bajos ingresos requieren ser asistidos, aunque la forma de hacerlo no sea fácil.

Economía energética es una rama multidisciplinaria que estudia las condiciones de producción, distribución y utilización de la energía, ya sea como factor de producción, bien de consumo final o fuente de financiamiento.

Por otra parte, la teoría económica del consumidor, señala que un individuo adquiere bienes y servicios acorde con la mayor utilidad sujeta a una restricción presupuestal. Hogares de altos ingresos serán más propensos a adquirir bienes durables, "ahorradores de energía" que los de bajo ingreso.

Partiendo de una base microeconómica de naturaleza inelástica, la función consumo eléctrico residencial presenta, en el caso de regiones como la que constituye nuestro caso de estudio, un considerable contenido estacional. Tratándose de un elemento básico del bienestar social familiar, los resultados estadísticos de las investigaciones realizadas, han permitido 
situar con suficiente grado de precisión, que la demanda eléctrica se asocia positivamente con el nivel socioeconómico del hogar durante los meses de verano.

Sin embargo, debe reconocerse que la proporción explicada de la varianza del consumo, es aún insuficiente para considerar los elementos independientes como determinantes en su comportamiento. Con esto se indica que el grado de ajuste es bajo y sugiere que deben incluirse factores adicionales en la explicación del fenómeno.

Los resultados de la aplicación del método de regresión en el examen de los determinantes del consumo, revelan que las variables convencionales de naturaleza técnica o puramente microeconomica, resultan insuficientes para explicar el comportamiento observable en los consumos durante el verano. Ello sugiere la incorporación de un conjunto amplio que identifique el tipo de actividad que se realiza (patrones de utilización y estilo de vida familiar).

Las múltiples dimensiones de la vida social requieren adoptar con seriedad mayores consideraciones de índole ambiental. El recurso tarifario podrá atender con eficiencia y paulatinamente, los estímulos para inducir al ahorro de energía, acompañando así los elementos anteriores con un marco que ofrezca condiciones objetivas para la realización de metas factibles.

La definición de un proyecto productivo y social orientado en esta dirección, resulta de la mayor importancia en la perspectiva de poder ofrecer mejores condiciones económicas y ambientales para el desarrollo regional de centros de población en las zonas áridas septentrionales de nuestro país. 


\section{BIBLIOGRAFIA}

BOLTVINIK, Julio. 1984. "Satisfacción desigual de las necesidades esenciales en México" en La desigualdad en México, Siglo XXI Editores, México.

CAMPERO L, Eduardo, Jorge Ortiz S., Julia Vargas S. 1988. "Aspectos sobre el uso de la energía en el sector residencial en México". Depto. de Energía y Comisión de Apoyo y Desarrollo Académico. Universidad Autónoma Metropolitana-Azcapotzalco. Memorias de la I Reunión Nacional Sobre la Energía y el Confort. Mexicali, B.C., p. 208-211.

COMISIÓN FEDERAL DE ELECTRICIDAD. 1990. "Programa de apoyo a la economía familiar y de ahorro de energía eléctrica", en La crónica de Baja California, diario regional, 8 de diciembre.

- 1991. Estadísticas por entidad federativa, México.

CRAY, Randy F. 1989. "Estimating the Impact of Higher Electricity Rates on Intersectoral Prices: an Input-Output Approach", The Review of Regional Studies, p. 18-28.

DAGUM, Camilo. 1970. "Un modelo econométrico de la oferta y demanda de energéticos: estudio del caso de México", El trimestre Económico, Fondo de Cultura Económica, p. 275-300.

DE ALBA, Edmundo. 1988. "Política nacional sobre la investigación y fuentes alternas de energía", SEMIP, en Memorias de la I Reunión Nacional sobre la Energía y el Confort, UABC, p. 296-301.

DURHAM, Catherine, Bomice Colby, G. y Molly Longstreth. 1988. "The Impact of State Tax Credits and Energy Prices on Adoption of Solar Energy Systems", Land Economics, vol. 64, núm. 4, noviembre, p. 347-355.

ESPARZA León, Manuel Miguel. 1988. "El ahorro de energéticos, la investigación y el desarrollo tecnológico: una agenda para Baja California", UABC, Memorias de la I Reunión Nacional Sobre la Energía y el Confort, Mexicali, B.C, p. 250-253.

FIGUEROA Noriega, Luis R. 1988a. "Consideraciones legales para el uso racional de la energía", Comisión Federal de Electricidad, Memorias de la I Reunión Nacional Sobre la Energía y el Confort, Mexicali, B.C, p. $262-266$.

- 1988b. "Las tarifas eléctricas y la administración de la demanda". Comisión Federal de Electricidad. Memorias de la I Reunión Nacional Sobre la Energía y el Confort. Mexicali, B.C., p. 268-275

FRI, Robert, W. 1989. "Energía y ambiente: conflicto en puerta?". Revista Facetas, p. 33-36. 
HAGERMAN, RobertL. y Brian T. Ratchford. 1978. "Some Determinants of Allowed Rates of Return on Equity to Electric Utilities", Bell Journal of Economics, núm. 9, primavera, p. 46-55.

HARRIS, Malcolm C. y Peter Navarro. 1983. "Does Electing Public Utility Comissioners Bring Lower Electric Rates?" Public Utilities Fortnightly, 112, septiembre, p. 23-27.

HENNESY, Michael y Dennis M. Keane. 1989. "Lifeline Rates in California: Pricing Electricity to Attain Social Gaols", Evaluation Review, vol. 13, núm. 2, abril, p.123-140.

HERTEL, Thomas W. y Timothy D. Mount. 1985. “The Pricing of Natural Resources in a Regional Economy", Land Economics, vol.61, núm. 3, agosto, p. 229-243.

LUNA LASTRA, Héctor. 1988. "Energía nuclear: una alternativa en el desarrollo energético nacional", CFE, en Memorias de la I Reunión Nacional sobre la Energía y el Confort, UABC, p. 302-306.

MANN, Patrick C. 1974. "User Power end Electricity Rates", Journal of Law and Economics, núm. 17, octubre, p. 433-443.

MORSS, M.F. y J.L. Small. 1989. "The Effect of Wood and Coal Stoves on Household Use of Electricity", Land Economics, vol. 65, núm. 1, febrero, p 29-37.

NELSON, Randy A. y Walter Primeaux Jr. 1988. "The Effects of Competition on Transmission and Distribution Costs in the Municipal Electric Industry", Land Economics, vol. 64, núm. 4, noviembre, p. 338-346,

PERLÓ, Manuel. 1990. “¿Deben terminarse los subsidios?”, Revista Demos, p.30-32.

PONCE, Antonio y Esteban Silva. 1989. "Calor y política: tarifas eléctricas en zonas cálidas" en Perfil de La jornada, 8 de julio, Centro de Investigaciones Económicas y Sociales, Universidad de Sonora.

POSNER, Richard A. 1974. "Theories of Economic Regulation", Bell Journal of Economics, núm. 5, Autumm, p 335-358.

PRIMEAUX, Walter J. 1975. "A Reexamination of the Monopoly Market Structure for Electric Utilities" en Promoting Competititon in Regulated Markets, ed A. Phillips, Washington D.C. The Brookings Institution.

- 1977. "An Assessment of X-Efficiency Gained through Competition", The Review of Economics and Statistics, LIX, febrero, p.105108 .

- 1986. Direct Electric Utility Competition, Nueva York, Praeger Publishers. 
PRIMEAUX, Walter J. Jr. y Randy A. Nelson. 1980. "An Examination of Price Discrimination and Internal Subsidization by Electric Utilities", Southern Economic Journal, núm. 47, julio, p. 84-99.

PRIMEAUX, Walter J. Jr. y Patrick C. Mann. 1986. "Regulator Selection Methods and Electricity Prices", Land Economics, vol. 62, núm. 1, febrero, p. 1-13.

RIDGE, Richard S., Gary A. Stern y Ronald K. Watts. 1990. "Econometric Model Evaluation: Implications for Program Evaluation", Evaluation Review, vol. 14, núm. 3, junio, p. 308-314. RIVAS López, Moisés, 1990. "Estudio de la demanda de energía eléctrica: aspecto conceptual", Instituto de Ingeniería UABC, Memorias de la II Reunión Nacional sobre la Energía y el Confort, Mexicali, Baja California, p. 83-86.

ROBERTS, Mark J. 1986. "Economics of Density and Size in the Production and Delivery of Electric Power"',Land Economics, vol. 62 , núm. 4 , noviembre, p.378-387.

SAMUELS, Warren, J. 1973. "Public Utilities and the Theory of Power" en Perspectives in Public Regulation: Essays on Political Economy, ed. Milton Russell. Carbondale; Southern Illinois University Press.

Secretaría de Desarrollo. 1992. Estadísticas básicas de Baja California, diciembre.

SEXTON, Richard J., Terri A. Sexton, Joyce Jong-Wen Wann, y Catherine L. Kling. 1989. "The Conservation and Welfare Effects of Information in a Tome-of-day Pricing Experiment"', Land Economics, vol. 65, núm. 3, agosto, p. 1-8.

SPP. 1979. Encuesta nacional de ingresos y gastos de los hogares, México.

STIGLER, George J. 1971. "The Theory of Economic Regulation", Bell Journal of Economics, núm. 2, primavera, p. 213-217.

TREBING, Harry M. 1981. "Equity Efficiency and the Viability of Public Utility Regulation", Applications of Economic Principles in Public Utility Industries, eds. Thomas G. Gies y Werner Sichel, Graduate School of Business Administration, University of Michigan.

$\mathrm{UABC}$, Instituto de Investigaciones Sociales, (1989) Encuesta de impacto del consumo de energía en el gasto familiar, mecanoescrito.

UABC-Instituto de Investigaciones Sociales, CFE, XIII Ayuntamiento de Mexicali. 1990. Encuesta sobre adecuación ambiental de la vivienda y consumo eléctrico en Mexicali.

URTEAGA Dufour, José Antonio. 1988. "La economía energética: una disciplina de estudio", Instituto Mexicano del Petróleo, Memorias. 
de la I Reunion Nacional sobre la Energía y el Confort, Mexicali, Baja California, p.152-155.

VELASCO, I, Ambriz, J.J y H. Romero. 1988. "Bienestar y energía", Universidad Autónoma Metropolitana, Memorias de la Reunión Nacional Sobre la Energía y el Confort, Mexicali, B.C. p. 84-89. WIONCZECK, Miguel S. 1982. "Limitaciones de la política energética de México", en Energía en México. Ensayos sobre el pasado y el presente, El Colegio de México.

WRIGHT, James D. 1988. "Survey Research and Social Policy", Evaluation Review, vol. 12, núm. 6, diciembre, p. 595-606.

YERGIN, Daniel. 1989. "Cuestiones energéticas para los 90". Revista Facetas, núm. 85. p. 17-23. 